\title{
Inflación semanal en galletitas: un enfoque de datos de panel
}

\author{
MELLER, LEANDRO \\ Universidad Nacional del Sur (Argentina) \\ Correo electrónico: leandro.meller@uns.edu.ar \\ LARROSA, JUAN M.C. \\ Universidad Nacional del Sur (Argentina) \\ Correo electrónico: jlarrosa@uns.edu.ar \\ DELBIANCO, FERNANDO \\ Universidad Nacional del Sur (Argentina) \\ Correo electrónico: fernando.delbianco@uns.edu.ar \\ RAMÍREZ MuÑoZ dE TORO, GONZALO \\ Universidad Nacional del Sur (Argentina) \\ Correo electrónico: grrmdt@gmail.com \\ URIARTE, JUAN IGNACIO \\ Hyperia (Argentina) \\ Correo electrónico: juanibbca@gmail.com
}

\begin{abstract}
RESUMEN
El objetivo de este trabajo es evaluar la dinámica semanal de precios del sector de galletitas en el marco de una economía con inflación moderada, tal como lo es la argentina. Empleando datos de frecuencia semanal, se estiman cinco versiones de la función que relaciona a la variación semanal de los precios de las galletitas con sus posibles determinantes. Cuatro de esas estimaciones han sido obtenidas mediante mínimos cuadrados generalizados (MCG), en tanto que la restante corresponde a una especificación con efectos aleatorios (EA). Se identificaron posibles influencias del nivel de concentración de la oferta, las características de cada producto (tamaño, sabor, tipo), la situación del mercado cambiario, ciertos efectos temporales y las variaciones en los precios de los insumos sobre la dinámica de precios de las galletitas. Sin embargo, solamente los efectos de las variaciones en los precios de los insumos se presentaron robustos. El signo de estos efectos robustos coincide siempre con el esperado, a excepción del caso de la harina de trigo.
\end{abstract}

Palabras clave: galletitas, fijación de precios, inflación, Argentina, datos en línea.

Clasificación JEL: C33; L11; L13.

MSC2010: 62007; 91B84; 91B24.

Artículo recibido el 29 de octubre de 2019 y aceptado el 2 de julio de 2020. 


\title{
Weekly Cookie Inflation: A Panel Data Approach
}

\begin{abstract}
The objective of this contribution is to evaluate the weekly price dynamics of the biscuit sector in the framework of an economy with moderate inflation, such as Argentina. Using weekly frequency data, five versions of the function that relate cookie price weekly variations with their possible determinants are estimated. Four of these estimates have been obtained using generalized least squares (GLS), while the rest corresponds to a specification with random effects (RE). Possible influences of the supply level concentration, the features of each product (size, flavour and type), the exchange market situation, certain temporary effects and the variations in the prices of inputs on the price dynamics of the cookies are identified. However, only the effects of changes in input prices were robust. The sign of these robust effects always coincides with the expected values, with the exception of the case of wheat flour.
\end{abstract}

Keywords: biscuits, pricing, inflation, Argentina, online data.

JEL classification: C33; L11; L13.

MSC2010: 62007; 91B84; 91B24.

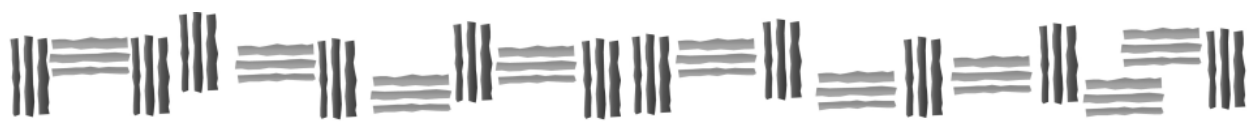




\section{Introducción.}

El presente trabajo exhibe resultados estadísticos relevantes para el estudio de un tema de suma importancia: la evolución de los precios de las galletitas en Argentina. Basta con hacer sólo algunas observaciones sobre los mercados de estos productos en general para poner en evidencia el hecho de que son lo suficientemente importantes como para considerarlos merecedores de un análisis como el que se puede encontrar en los siguientes párrafos.

Las galletitas son alimentos panificados que, al igual que el resto de sus congéneres, se producen con base en harinas y otros ingredientes (Nandeshwar et al., 2017) para el consumo cotidiano de las familias en la mayoría de los países. La facilidad de su producción en serie y su almacenamiento hace que sean siempre un competitivo integrante de las dietas, incluso de las clases con menores ingresos (Burns et al., 2013). Merece mencionarse además que el rubro en cuestión, sobre todo en sus versiones saladas (Beets et al., 2015), muestra un fuerte incremento en Estados Unidos (IRi, 2018), donde es demandado principalmente por la población estudiantil (Byrd-Bredbenner et al., 2012).

Diversas críticas se han esgrimido respecto al grado de bondad de su consumo, sobresaliendo las que se basan en un análisis de los diversos componentes ultraprocesados que las componen (Anders \& Ahmad, 2011). En Brasil, específicamente, Machado et al. (2017) destacan este rol de comida ultraprocesada de las galletitas, entre otros alimentos, y la inelasticidad de su precio respecto a las calorías portadas.

Las características mencionadas (facilidad en la producción y la distribución, por un lado, y baja elasticidad del precio respecto de las calorías portadas, por otro) han contribuido a la conversión de las galletitas en productos de alta rotación en las góndolas (Mehra, 2017, para el caso de la India). Es probable que estas características también hayan tenido alguna influencia en el hecho de que se producen de muy diversas formas (Rai et al., 2017), desde altamente industrializadas hasta en series muy cortas y artesanales.

En Argentina, por su parte, su consumo representa uno de los más altos del mundo (Clarín, 2011), con cerca de 10 kilogramos por año por individuo, y el sector que las produce factura unos $\$ 3.800$ millones anuales en ventas, con exportaciones hacia 2010 del orden de los US\$296 millones. El IPC del INDEC ubica a las galletitas dentro del grupo de los Panificados, rubro que abarca gran parte de los productos comestibles en que se transforma diariamente a la harina (panes en diferentes formas, facturas y alfajores), y asigna un ponderador de $3,06 \%$ a este tipo de productos como porcentaje de gasto de las familias. Es decir, su variación agregada y ponderada transmite ese porcentaje al nivel general de inflación de cada período.

El presente trabajo busca evaluar la dinámica semanal de precios del sector de galletitas o galletas en el marco de una economía con inflación moderada, tal como lo es la argentina. Partiendo de una base de datos de precios de galletitas obtenidos semanalmente se buscó explorar qué determinantes dan forma a la fijación de precios de estos productos, prestando especial atención a determinantes estructurales y coyunturales de la inflación argentina. Utilizando el raspado de datos (web scraping) de alta frecuencia, una metodología reciente y ampliamente utilizada para recabar información procesable (Cavallo, 2013), se reunieron datos de precios semanales y se complementó esta información con precios de bienes sustitutos, variables del mercado externo (tipo de cambio), indicadores de la estructura del mercado y factores asociados a la temporalidad (estacionalidad y efecto semanal).

La significatividad de la asociación entre las variaciones de los precios y sus posibles determinantes puede ser el síntoma de un contexto de expectativas de inflación de muy corto plazo presentes. Es decir, si variaciones en los determinantes se asocian a una rápida respuesta en precios, el resultado en cuestión puede ser un indicativo de una alta elasticidad temporal a estos cambios, producto de muy sensibles expectativas de ajuste de precios. Ello puede enmarcarse en un proceso de creciente inflación general o puede deberse a shocks sectoriales específicos. 
Un resultado interesante de este trabajo es el hecho de que dependiendo del modelo econométrico elegido surgen diversos determinantes que afectan la variación de precios semanal de este mercado específico. Por ejemplo, el grado de concentración de la oferta juega un rol significativo en algunos modelos, en los que está asociado a tasas de variación de precios más altas. Un hecho similar se verifica con ciertas características del producto, como su composición, ya que al menos un modelo sugiere que los precios de las galletitas de chocolate aumentaron en mayor medida. Por otra parte, las galletitas de agua, las obleas y las rellenas parecen haber aumentado más aceleradamente que los precios de las crackers, aunque se observa que dichos resultados no se presentan robustos frente a todas las especificaciones probadas.

Otro resultado interesante es que se detectan alzas asociadas a patrones temporales específicos, así como también se observa una relación significativa con un indicador de inestabilidad cambiaria. En cuanto a los insumos, las variaciones de precios en los huevos, la leche y los combustibles tienen los signos esperados, contrariamente a lo que sucede con las variaciones de precios en la harina de trigo, cuestión que se discute más adelante.

El trabajo continúa con la sección 2, donde se realiza una revisión de literatura de estudios sobre el sector galletitas en la literatura académica. Luego se procede al desarrollo de la sección 3, en la que se presentan y describen los datos referidos a la variable dependiente del modelo econométrico, cuyas variables explicativas se presentan en la sección 4. Esta última sección contiene también los resultados de las estimaciones y un análisis de la significatividad de los coeficientes hallados. Finalmente, la sección 5 cierra el trabajo con las conclusiones.

\section{Literatura relevante.}

La mayor parte de la literatura económica consultada para el estudio de los mercados de galletitas versa sobre cuestiones como su comercialización, la volatilidad de sus precios, la estructura de los mercados donde se comercializan o la influencia de la regulación sobre el sistema de fijación de sus precios. Los párrafos que siguen presentan una brevísima reseña de lo que se ha escrito sobre cada uno de estos temas, comenzando por lo que se ha escrito sobre las prácticas de comercialización de galletitas y su evolución a través del tiempo.

Las galletitas tienen una larga historia de utilización como ración militar en forma de un pan duro o galleta. Con la prolongación de los conflictos, este hábito provocó cambios en los gustos de los veteranos, quienes comenzaron a demandar productos similares en tiempos de paz (Santlofer, 2007). El nacimiento del empaquetamiento moderno hizo de este alimento seco un candidato ideal para ser presentado en las góndolas de los grandes almacenes (Hisano, 2017) y posteriores supermercados (Borg, 2013). Las marcas jugaron un rol trascendente en el desarrollo de estos mercados desde sus inicios (French, 2017). Por ejemplo, intervinieron activamente en el desarrollo progresivo de formas de empaquetamiento (Tweede, 2012), las cuales, como Vergura y Luceri (2017) han demostrado, afectan la decisión de compra del consumidor. El origen de otras tácticas de comercialización que terminaron aplicándose al sector de galletitas puede ser encontrado en Williams y Williams (2017), en tanto que una revisión histórica de estrategias de marketing aplicadas al mercado de galletitas puede consultarse en Ramli (2017).

Si bien los cambios en los precios de los insumos suelen trasladarse directamente hacia los precios de los bienes finales, sobre todo desde la crisis internacional de alimentos en 2007 (Yang et al., 2015), este sector conserva cierta volatilidad específica. Chadwick y Bastan (2017) investigan si variaciones inesperadas en los precios de los alimentos afectan de manera asimétrica a su volatilidad. Trabajando con datos de Turquía entre enero de 2003 y enero de 2017, encontraron que en el caso de las galletitas la varianza del precio que se espera en el futuro, dada la información disponible en el presente, es constante, lo que implicaría que las variaciones inesperadas en el precio de las galletitas no afectan al grado de volatilidad de dicho precio. Los autores creen que este peculiar comportamiento se debe a que las galletitas se comercializan en un mercado maduro, en el que la ausencia de incentivos a 
obtener ganancias extra dificulta la competencia y la entrada, lo que se traduciría en mayor estabilidad de precios a corto plazo.

El poder de mercado ha sido frecuentemente estudiado en el mercado de galletitas. Perekhozhuk, et al. (2016) hacen un recorrido de los principales trabajos donde se ha estimado empíricamente la existencia de "poder de mercado" en los sectores agrícola y de producción de alimentos en general. O’Donnell et al. (2007) también plantean una contribución sobre las galletitas, entre otros sectores analizados. Sin embargo, a diferencia de los verdaderos mercados de galletitas u otros productos panificados, los modelos elaborados por estos autores asumen que el producto objeto de transacción es homogéneo. Coloma (2007), en cambio, estimó el efecto de la fusión de Bagley y Arcor, ocurrida entre fines del año 2004 y principios del 2005, sobre el mercado argentino de galletitas. Para ello, construyó un modelo que representara el comportamiento de este mercado oligopólico y estimó el valor de sus parámetros con datos mensuales del período enero de 2003 - marzo de 2006. Los resultados hallados por este autor sugieren que la reducción de costos obtenida mediante la fusión compensa con creces el aumento en los precios inducido por la misma, por lo que la fusión habría resultado, en términos netos, beneficiosa para los consumidores. Otro rasgo interesante de este artículo es la descripción que su autor hace del mercado de galletitas argentino, que incluye caracterizaciones tanto de los oferentes como de los bienes transados.

Por otra parte, la regulación del mercado puede afectar también la forma de fijación de precios del sector. Symeonidis (2017) investiga si la competencia entre las empresas de un sector industrial hace que las huelgas sean más frecuentes e intensas en dicho sector. Para responder al referido interrogante, analizó la historia de algunos sectores industriales en el Reino Unido. En el caso del pan, la harina y las galletitas, el autor observó que antes de que se promulgara la Restrictive Trade Practices Act (1956) las prácticas anticompetitivas eran muy frecuentes en este sector. Tras dicha modificación legislativa, las mencionadas prácticas iniciaron un paulatino proceso de desaparición. Por ejemplo, en 1959 fue abandonado el acuerdo por el que la National Association of Biscuit Manufacturers fijaba el precio de las galletitas, y a principios de los años 60 cesaron los arreglos para fijar el precio de sus insumos clave y sus productos secundarios. Según los resultados de su investigación, tras estos acontecimientos la cantidad y la intensidad de las huelgas se deben haber incrementado en dicho sector.

Puede observarse que las contribuciones relevadas no aportan información respecto a datos de alta frecuencia, tales como datos semanales, y que poseen limitada información respecto al mercado argentino. Tampoco abordan la posibilidad de que exista una asociación estadística de muchas y diversas particularidades de los productos-marcas galletitas (como la composición, el peso o el tipo, entre otros) con el precio de las mismas.

La disponibilidad de datos semanales, una novedad para los autores estudiados, permitiría investigar si la estructura de mercado ejerce algún rol específico en la fijación de precios de galletitas a nivel semanal. También permitiría responder esa misma pregunta pero respecto de aquellos determinantes que se mencionan en el párrafo anterior. Usando datos de Argentina, las próximas secciones de este trabajo muestran qué patrones se pueden observar y qué rol puede ser percibido de diversos determinantes microeconómicos clásicos a esta frecuencia datos específica, todo ello dentro del marco de una economía con inflación de moderada a alta (entre 20 y $50 \%$ de inflación interanual para el período de análisis) (Drenik \& Pérez, 2020; Miranda-Zanetti et al., 2019).

A continuación, es desarrollada una serie de modelos econométricos para intentar observar qué regularidades emergen a nivel semanal en el mercado de galletitas en el contexto de una economía como la argentina.

\section{Datos y estimaciones.}

Las variables explicadas que se utilizarán en el presente trabajo comprenden la evolución semanal de los precios de 273 variedades de paquetes de galletitas (DG) durante el período comprendido entre el 
1/12/2015 y el 31/12/2018. Los datos fueron obtenidos a través del proyecto IPC Online (Uriarte et al., 2019) de relevamiento de precios a través de raspado de red en diversos supermercados con sucursal en Bahía Blanca (https://ipconlinebb.wordpress.com/). Los datos se relevaron semanalmente comprendiendo cada semana las fechas $1-7,8-14,15-21$ y $22-28$ de cada mes.

Los datos de variación de precios del agrupamiento de "Panificados" se exhiben en la Tabla 1. Se presentan la media, la mediana, el desvío estándar, el coeficiente de asimetría y la curtosis de las variaciones de los precios. Como se observa, los ítems con alzas más pronunciadas son "Pan francés tipo miñón" y "Alfajor", seguido de "Galletitas de agua envasadas". Obsérvese que la variabilidad semanal es alta comparada con su media, y esa misma variabilidad se puede observar en los coeficientes de asimetría y curtosis. En el primer caso, la mayoría de los valores muestran una distribución asimétrica positiva, con excepciones como "Galletitas dulces envasadas con relleno" impulsando al subgrupo "Galletitas dulces" hacia una distribución asimétrica negativa, es decir, la distribución de variaciones sesgada hacia valores más altos que la media aritmética. Mientras que en el segundo caso la curtosis asume valores positivos (distribuciones leptocúrticas), altamente concentrada en los valores de la media aritmética.

Tabla 1. Estadística descriptiva de la variación de precios de los componentes del grupo Panificados.

\begin{tabular}{lccccc}
\hline Categoría & Media & Mediana & $\begin{array}{c}\text { Desviación } \\
\text { estándar }\end{array}$ & $\begin{array}{c}\text { Coeficiente } \\
\text { de asimetría }\end{array}$ & Curtosis \\
\hline Productos de panificación & $0,72 \%$ & $0,28 \%$ & $2,18 \%$ & 3,18 & 19,52 \\
Pan fresco & $0,79 \%$ & $0,00 \%$ & $4,02 \%$ & 3,01 & 20,76 \\
Pan francés tipo miñón & $1,11 \%$ & $0,00 \%$ & $6,50 \%$ & 7,47 & 69,67 \\
Pan francés tipo flauta & $0,89 \%$ & $0,00 \%$ & $6,34 \%$ & 3,47 & 42,72 \\
Pan envasado & $0,28 \%$ & $0,00 \%$ & $1,92 \%$ & 0,75 & 7,23 \\
Pan lacteado & $-0,09 \%$ & $0,00 \%$ & $2,93 \%$ & $-2,29$ & 10,69 \\
Pan de Viena & $0,47 \%$ & $0,00 \%$ & $2,25 \%$ & 0,88 & 7,53 \\
Pan rallado & $0,55 \%$ & $0,00 \%$ & $3,43 \%$ & 0,99 & 6,32 \\
Facturas & $0,79 \%$ & $0,00 \%$ & $4,24 \%$ & 6,66 & 55,39 \\
Galletitas dulces * & $0,67 \%$ & $0,46 \%$ & $1,83 \%$ & $-1,07$ & 9,38 \\
Galletitas dulces envasadas con relleno * & $0,78 \%$ & $0,30 \%$ & $3,63 \%$ & $-4,00$ & 43,22 \\
Galletitas dulces envasadas sin relleno * & $0,61 \%$ & $0,00 \%$ & $2,78 \%$ & 0,59 & 10,29 \\
Alfajor & $1,10 \%$ & $0,61 \%$ & $1,75 \%$ & 1,20 & 2,35 \\
Otras galletas y galletitas * & $0,65 \%$ & $0,24 \%$ & $1,87 \%$ & 3,39 & 24,68 \\
Galleta marinera * & $0,53 \%$ & $0,00 \%$ & $2,54 \%$ & 5,15 & 29,32 \\
Galletitas de agua envasadas * & $0,90 \%$ & $0,30 \%$ & $1,63 \%$ & 1,74 & 5,48 \\
Galletitas de harina integral * & $0,53 \%$ & $0,00 \%$ & $5,19 \%$ & 3,99 & 37,06 \\
Vainillas & $0,35 \%$ & $0,00 \%$ & $1,94 \%$ & 3,86 & 22,96 \\
Productos de pastelería & $-0,05 \%$ & $0,00 \%$ & $3,14 \%$ & $-9,36$ & 101,98 \\
Tarta dulce & $-0,05 \%$ & $0,00 \%$ & $3,14 \%$ & $-9,36$ & 101,98 \\
\hline & & & & &
\end{tabular}

Nota: * representan las categorías estudiadas en este trabajo.

Fuente: Elaboración propia. 
Teniendo en cuenta la contribución de Martínez et al. (2002), cuyo experimento de sensibilidad respecto a diversas características de las galletitas crackers revela agrupamientos de consumidores en función de diversos atributos de las mismas (entre otros hallazgos), se hace necesario identificar si efectivamente estas características afectan a la evolución de precios, por lo que resulta importante distinguir las variedades de galletitas con el mayor detalle posible. El modo elegido para conseguir esta distinción consistió en agregar, a los datos descriptos, variables relativas a las características de cada producto-marca.

\section{Modelo econométrico y resultados.}

Con la serie de precios de cada paquete de galletitas, definido por su tamaño, marca y características distintivas, se construyó un panel de datos. Para evaluar el efecto de diversos determinantes en la dinámica semanal de precios se propone un modelo econométrico general que tome en cuenta variables relevantes medidas en frecuencia semanal y, sobre todo, que permita responder las preguntas realizadas en las secciones anteriores:

$$
P_{i t}=f\left(V C_{i}, E X_{t}, E T_{t}, I_{t}\right)
$$

Las variables dependientes $\left(P_{i t}\right)$ representan la evolución de los precios de los 217 productosmarca de galletitas. De acuerdo al modelo general propuesto, dichas variables dependen de características propias de cada producto-marca $\left(V C_{i}\right)$, variables que representan al mercado cambiario $\left(E X_{t}\right)$, diversas variables de efecto temporal (semanal, mensual y anual) para capturar efectos estacionales $\left(E T_{t}\right)$ y finalmente la evolución del precio de los insumos $\left(I_{t}\right)$.

A continuación, se presenta una lista de las variables empleadas. Es importante advertir que no todas ellas fueron incluidas en todas las estimaciones.

Variable $P_{i t}$

- Evolución semanal de los precios de los 273 productos-marcas de galletitas vendidas en góndola.

\section{Variables $V C_{i}$}

Estas variables proceden en su mayoría del ejercicio de web scrapping, y se caracterizan por carecer de variabilidad within. Esto último es muy importante, porque implica que se perderían ante una transformación de efectos fijos, y es más importante aún si se tiene en cuenta además que son las variables que previamente se mencionaban como de interés. Más adelante se volverá sobre esta cuestión.

- IHH: Índice de Herfindahl-Hirschman para cada empresa, formado por la cuota de mercado. Mediante la inclusión de esta variable se pretende controlar la variación de precios semanales de cada paquete de galletitas por diversas características relacionadas con el poder de mercado de la empresa productora.

- Peso: Peso del paquete que distingue también segmentos específicos de mercado.

- Empresa: Empresa productora de la galletita. Comprende las siguientes firmas: Arcor, Bagley, Gold Mundo, Granix, Great Value, Kapac, Lía, Mondelez, Okebón, Pepsi, Santa María, Tía Maruca, Valente, Vea, Otra. 
- Feature: Si posee alguna característica particular que podría afectar el precio, como la presencia de chocolate, frutilla o semillas.

- Type: Crackers, de Agua, Integrales, Marineras, Obleas, Rellenas, Rosquitas, Secas, Tipo María.

Variables $E X_{t}$

Esta categoría incluye variables de control procedentes del mercado cambiario y diversas métricas de las series de cotización del dólar comprador y vendedor de la casa Pullman de Bahía Blanca. Las utilizadas en las estimaciones de este trabajo se listan a continuación.

- Variación precio compra: Variación porcentual semanal en el precio de compra del dólar.

- Desvío estándar intrasemanal precio compra: Indicador de volatilidad cambiaria.

- Skewvc: Coeficiente de asimetría de la variación en el precio de compra. Indicador de volatilidad cambiaria.

\section{Variables $E T_{t}$}

Este grupo abarca a todas aquellas variables binarias agregadas para capturar algún efecto temporal, cambio estructural o particularidad asociable a alguna semana (e.g. semanas que contengan días festivos):

- Dummy semanal: Binaria para semana 1, 2 y 3 de cada mes. Semana de referencia: semana 4 cada mes.

- Dummy anual: Binaria para cada año distinto del año de referencia. Año de referencia: 2016.

\section{Variables $I_{t}$}

Las variables de esta categoría son determinantes de la variación de precios incluidas en el análisis como precios de los insumos. Ante la carencia de datos semanales de precios mayoristas, se intentó aproximar a los precios de los insumos mediante la evolución de sus contrapartes minoristas, específicamente harina, huevos, leche y combustibles en datos semanales.

- Harina de trigo: Precio minorista de la harina de trigo como proxy de la evolución del precio mayorista.

- Huevos: Precio minorista de los huevos.

- Leche fresca entera sachet: Precio minorista de la leche fresca más económica.

- Combustibles y lubricantes: Precio minorista de los combustibles (nafta, gasoil, gnc).

La estadística descriptiva de las series de tiempo se presenta en el Apéndice al final del trabajo, primero de manera general y luego divida por efectos within y between. Es importante mencionar, por otra parte, el hecho de que como la mayoría de las variables son variaciones porcentuales de precios (tanto de las galletitas como de los insumos o controles) o variables indicativas (como sabores, empresa, etc.) las series resultaron estacionarias al realizar la prueba de raíz unitaria en paneles (xtuniroot) (Baltagi, 2012).

Fueron estimadas cinco versiones del modelo general presentado al principio de la sección. Cuatro de ellas fueron obtenidas mediante Mínimos Cuadrados Generalizados (MCG), ajustando por la auto correlación entre cada panel (i.e. la inercia temporal del producto), y la correlación entre paneles 
(la dependencia de movimientos de precios) (Greene, 2012). Lo que diferencia a cada una de las versiones respecto de las demás es el conjunto de variables explicativas seleccionadas, tal y como puede observarse en las Tablas 2 y 3.

La característica principal del panel que inclina la decisión a estimar por MCG es que, por un lado, es un panel largo (más de 140 observaciones de precio semanal) y, por otro lado, la gran mayoría de las variables de interés (i.e. características del producto) no varían en el tiempo, por lo que la transformación de efectos fijos las eliminaría de la regresión. Esto hace que, por un lado, sea poco fiable una estimación de corte transversal más clásica (pooled, fixed o random) debido al impacto de rezagos de las variables tanto dependientes como explicativas, mientras que debido a la gran cantidad de rezagos tampoco es viable un análisis de paneles dinámicos al estilo de Arellano y Bond (1991) o Blundell y Bond (1999), donde se instrumentan con diferencias y niveles de los rezagos, ya que la calidad de los instrumentos se ve comprometida si se instrumenta con todos los rezagos, y la elección de una cantidad de rezagos sería completamente ad-hoc (Greene, 2012).

En las regresiones se incluye el modelo de Efectos Aleatorios (EA) como control porque muchas variables desaparecen si se estima por Efectos Fijos (variables como sabor o empresa, entre otras, se anulan con la transformación). El Test de heterocedasticidad en paneles (Sosa-Escudero \& Bera, 2008) indica la presencia de heterocedasticidad, validando la especificación MCG, y demostrando que sería inválido estimar por medio de un efecto aleatorio estándar. Por otro lado, no se incluyó la regresión de Efectos Fijos por lo mencionado anteriormente, debido a que la resultante no sería un modelo comparable, y el test $\mathrm{F}$ que podría resultar de comparar Efectos Fijos versus EA no sería informativo (Cameron \& Trivedi, 2009).

Las Tablas 2 y 3 , ya mencionadas, presentan los resultados de dichas estimaciones. La primera de ellas contiene los coeficientes de dos modelos estimados mediante MCG (el primero de los que no incluye el efecto de las variaciones en el precio de la harina de trigo, en tanto que el segundo sí) y los resultados de la estimación del modelo con EA. La Tabla 3, por su parte, exhibe los resultados de las otras dos estimaciones mediante MCG, que se diferencian respecto de las anteriores por un cambio en el año de referencia de las variables temporales y la implementación de otras medidas de volatilidad en el mercado cambiario. Como se mencionó anteriormente, las estimaciones incluidas en el trabajo son el resultado final de testear autocorrelación y heteroscedasticidad y ser las que mejor ajustan a los datos.

Antes de proceder a la lectura del análisis de los resultados, es importante mencionar que, salvo que se indique lo contrario, en todos los casos se ha analizado la significatividad de los coeficientes tomando un $p$-valor del $10 \%$.

Tabla 2. Estimaciones de modelos de datos de panel.

\begin{tabular}{lccc}
\hline & MCG (1) & MCG (2) & EA (3) \\
Variables & $P_{i t}$ & $P_{i t}$ & $P_{i t}$ \\
\hline & & & \\
IHH & $3.27 \mathrm{e}-07^{* * *}$ & $3.29 \mathrm{e}-07^{* * *}$ & $1.10 \mathrm{e}-07$ \\
& $(4.42 \mathrm{e}-08)$ & $(4.45 \mathrm{e}-08)$ & $(3.39 \mathrm{e}-07)$ \\
Peso & $8.96 \mathrm{e}-05^{* * *}$ & $9.48 \mathrm{e}-05^{* * *}$ & 0.000189 \\
& $(3.13 \mathrm{e}-05)$ & $(3.07 \mathrm{e}-05)$ & $(0.000255)$ \\
Empresa $=$ 2, Bagley & $-.000804^{* * *}$ & $-.000770^{* * *}$ & -0.000976 \\
& $(0.000125)$ & $(0.000120)$ & $(0.000936)$ \\
Empresa $=$ 3, Gold Mundo & $-0.00358^{* * *}$ & $-0.00356^{* * *}$ & -0.00343 \\
& $(0.000331)$ & $(0.000326)$ & $(0.00293)$ \\
Empresa $=$ 4, Granix & $-0.00178^{* * *}$ & $-0.00180^{* * *}$ & -0.00210 \\
& $(0.000269)$ & $(0.000272)$ & $(0.00157)$ \\
Empresa $=$ 5, GreatValue & $-0.00353^{* * *}$ & $-0.00348^{* * *}$ & $-0.00354 *$
\end{tabular}




\begin{tabular}{|c|c|c|c|}
\hline Empresa $=6$, Kapac & $\begin{array}{c}0 \\
(0)\end{array}$ & $\begin{array}{c}0 \\
(0)\end{array}$ & $\begin{array}{l}-0.00430 * \\
(0.00250)\end{array}$ \\
\hline \multirow[t]{2}{*}{ Empresa = 7, Lía } & $-0.00270 * * *$ & $-0.00266 * * *$ & $-0.00273 * *$ \\
\hline & $(0.000106)$ & $(0.000108)$ & $(0.00133)$ \\
\hline \multirow[t]{2}{*}{ Empresa $=8$, Mondelez } & $-.000939 * * *$ & $-.000908 * * *$ & -0.000921 \\
\hline & $(0.000154)$ & $(0.000155)$ & $(0.00103)$ \\
\hline \multirow[t]{2}{*}{ Empresa = 9, Okebón } & $-0.00325 * * *$ & $-0.00320 * * *$ & $-0.00287 * *$ \\
\hline & $(0.000292)$ & $(0.000289)$ & $(0.00138)$ \\
\hline \multirow[t]{2}{*}{ Empresa $=10$, Otro } & $-0.00230 * * *$ & $-0.00228 * * *$ & -0.00203 \\
\hline & $(0.000163)$ & $(0.000160)$ & $(0.00135)$ \\
\hline \multirow[t]{2}{*}{ Empresa $=11$, Pepsi } & $2.82 \mathrm{e}-05$ & $6.07 \mathrm{e}-05$ & -0.00116 \\
\hline & $(0.000180)$ & $(0.000184)$ & $(0.00154)$ \\
\hline \multirow[t]{2}{*}{ Empresa $=12$, Santa María } & $-0.00351 * * *$ & $-0.00350 * * *$ & -0.00351 \\
\hline & $(0.000326)$ & $(0.000322)$ & $(0.00250)$ \\
\hline \multirow[t]{2}{*}{ Empresa = 13, Tía Maruca } & 0.000751 & 0.000758 & -0.000533 \\
\hline & $(0.000670)$ & $(0.000667)$ & $(0.00295)$ \\
\hline \multirow[t]{2}{*}{ Empresa $=14$, Valente } & -0.000396 & -0.000391 & $3.56 \mathrm{e}-05$ \\
\hline & $(0.000298)$ & $(0.000296)$ & $(0.00304)$ \\
\hline \multirow[t]{2}{*}{ Empresa $=15$, Vea } & $-0.00194 *$ & $-0.00218 * *$ & -0.00215 \\
\hline & $(0.00105)$ & $(0.00101)$ & $(0.00301)$ \\
\hline \multirow[t]{2}{*}{ Feature $=2$, frutilla } & $-0.00105 * * *$ & $-0.00107 * * *$ & -0.00109 \\
\hline & $(0.000182)$ & $(0.000181)$ & $(0.00111)$ \\
\hline \multirow[t]{2}{*}{ Feature $=3$, otros } & -0.000125 & -0.000127 & -0.000112 \\
\hline & $(8.12 \mathrm{e}-05)$ & $(8.25 \mathrm{e}-05)$ & $(0.000715)$ \\
\hline \multirow[t]{2}{*}{ Feature $=4$, semillas } & -0.000512 & -0.000448 & -0.00125 \\
\hline & $(0.000380)$ & $(0.000371)$ & $(0.00208)$ \\
\hline \multirow[t]{2}{*}{ Type $=2$, De agua } & $0.00254 * * *$ & $0.00246 * * *$ & 0.00237 \\
\hline & $(0.000211)$ & $(0.000374)$ & $(0.00240)$ \\
\hline \multirow[t]{2}{*}{ Type $=3$, Integrales } & $-0.000488 * *$ & -0.000570 & -0.000977 \\
\hline & $(0.000212)$ & $(0.000407)$ & $(0.00254)$ \\
\hline \multirow[t]{2}{*}{ Type $=4$, Marineras } & $8.05 \mathrm{e}-05$ & 0 & -0.000465 \\
\hline & $(0.000457)$ & $(0)$ & $(0.00281)$ \\
\hline \multirow[t]{2}{*}{ Type $=5$, Obleas } & $0.00880 * * *$ & $0.00882 * * *$ & 0.00336 \\
\hline & $(0.000276)$ & $(0.000413)$ & $(0.00286)$ \\
\hline \multirow[t]{2}{*}{ Type $=6$, Rellenas } & $0.000424 * *$ & 0.000360 & 0.000211 \\
\hline & $(0.000186)$ & $(0.000385)$ & $(0.00242)$ \\
\hline \multirow{2}{*}{ Type $=7$, Rosquitas } & 0 & 0 & -0.00224 \\
\hline & (0) & $(0)$ & $(0.00368)$ \\
\hline Type $=8$, Secas & -0.000137 & -0.000189 & -0.000418 \\
\hline & $(0.000273)$ & $(0.000390)$ & $(0.00247)$ \\
\hline Type $=9$, Tipo María & 0 & $-3.07 e-05$ & -0.000633 \\
\hline & $(0)$ & $(0.000449)$ & $(0.00284)$ \\
\hline Type $=10$, Variedades & 0 & 0 & -0.00205 \\
\hline & $(0)$ & $(0)$ & $(0.00315)$ \\
\hline Variación precio compra & $-0.0160 * * *$ & $-0.0138 * * *$ & $-0.0156^{* * *}$ \\
\hline & $(8.36 \mathrm{e}-06)$ & $(7.42 \mathrm{e}-06)$ & $(0.00309)$ \\
\hline Dummy semana 1 & $-0.00155 * * *$ & $-0.00139 * * *$ & $-0.00104 *$ \\
\hline & $(1.42 \mathrm{e}-06)$ & $(1.23 \mathrm{e}-06)$ & $(0.000543)$ \\
\hline Dummy semana 2 & $-0.00124 * * *$ & $-0.00122 * * *$ & $-0.00128 * *$ \\
\hline & $(1.45 \mathrm{e}-06)$ & $(1.25 \mathrm{e}-06)$ & $(0.000520)$ \\
\hline Dummy semana 3 & $-.000101 * * *$ & $-4.96 \mathrm{e}-05 * * *$ & 0.000511 \\
\hline & $(1.34 \mathrm{e}-06)$ & $(1.15 \mathrm{e}-06)$ & $(0.000516)$ \\
\hline ano2016 & $-0.0103 * * *$ & $-0.00991 * * *$ & $-0.0103 * * *$ \\
\hline & $(4.23 \mathrm{e}-06)$ & $(3.66 \mathrm{e}-06)$ & $(0.00119)$ \\
\hline ano2017 & $-0.0105 * * *$ & $-0.0102 * * *$ & $-0.0104 * * *$ \\
\hline & $(4.25 \mathrm{e}-06)$ & $(3.68 \mathrm{e}-06)$ & $(0.00118)$ \\
\hline ano2018 & $-0.00709 * * *$ & $-0.00685 * * *$ & $-0.00794 * * *$ \\
\hline
\end{tabular}




\begin{tabular}{lccc} 
& $(4.23 \mathrm{e}-06)$ & $(3.65 \mathrm{e}-06)$ & $(0.00117)$ \\
Harina de trigo & & $-0.0211^{* * *}$ & $-0.0166^{* *}$ \\
Huevos & & $(1.86 \mathrm{e}-05)$ & $(0.00756)$ \\
& $0.0318^{* * *}$ & $0.0335^{* * *}$ & $0.0392^{* * *}$ \\
Leche fresca entera sachet & $(1.60 \mathrm{e}-05)$ & $(1.39 \mathrm{e}-05)$ & $(0.00569)$ \\
& $0.0344 * * *$ & $0.0327 * * *$ & $0.0337 * *$ \\
Combustibles y lubricantes & $(1.61 \mathrm{e}-05)$ & $(1.39 \mathrm{e}-05)$ & $(0.00595)$ \\
& $0.0306 * * *$ & $0.0304 * * *$ & $0.0355^{* * *}$ \\
Constante & $(1.40 \mathrm{e}-05)$ & $(1.20 \mathrm{e}-05)$ & $(0.00512)$ \\
& $0.0140^{* * *}$ & $0.0138 * * *$ & $0.0140 * * *$ \\
& $(0.000230)$ & $(0.000405)$ & $(0.00283)$ \\
Observaciones & 40,404 & 40,404 & 40,404 \\
Cantidad de producto-marca & 273 & 273 & 273 \\
\hline Errores estándares entre paréntesis. $\| * * * \mathrm{p}<0.01, * * \mathrm{p}<0.05, * \mathrm{p}<0.1$ \\
Referencias: Empresa = Arcor; Feature $=$ chocolate; Type $=$ cracker; Dummy \\
semana = 4; Año = 2015
\end{tabular}

Fuente: Elaboración propia.

La primera observación que se extrae al analizar la Tabla 2 es que los valores de los coeficientes asociados al IHH pueden suscitar algunas controversias. Los valores obtenidos mediante MCG, por un lado, son positivos y significativos, lo que sugiere que a un mayor nivel de concentración de la oferta en el mercado de galletitas le corresponde un mayor nivel de inflación en ese mismo sector. Sin embargo, la estimación del modelo con EA, por su parte, arroja un valor que no es significativo, lo que puede ser interpretado como un indicio de que en la industria de las galletitas no existe una relación entre la estructura de mercado y el nivel de inflación. La contradicción entre los resultados recuerda al debate del que participaron Yordon (1961), DePodwin y Selden (1963), Weiss (1966), Lustgarten (1975a, 1975b), Jones y Laudadio (1990), Zaleski (1992) y otros autores, quienes no consiguieron responder definitivamente cómo la estructura de los mercados condiciona a las tasas sectoriales de inflación.

Los valores estimados mediante MCG del coeficiente asociado a la variable que representa al peso de cada paquete de galletitas sugieren la existencia de una correlación positiva y significativa entre el nivel de inflación en el sector y el peso del paquete ofrecido. Esto significa que los precios de los paquetes de galletitas más pesados habrían subido en mayor medida que los precios de los más livianos. Sin embargo, la estimación del modelo con EA arroja un coeficiente que no es significativo estadísticamente, lo que sugiere que los paquetes no habrían experimentado diferentes tasas de inflación de acuerdo a su peso. La conclusión dependerá de cuál de las especificaciones usadas sea la más representativa del mercado que se quiere analizar.

Las estimaciones obtenidas mediante MCG sugieren también que Bagley, Gold Mundo, Granix, Great Value, Lía, Mondelez, Okebón, Santa María y las empresas más pequeñas tienden a subir los precios de sus productos en medida significativamente menor que el Grupo Arcor. Las obtenidas para el modelo con EA, en cambio, parecen sugerir que tal conclusión sólo es válida respecto de los productos ofrecidos por Great Value, Kapac (excluidos de las estimaciones mediante MCG), Lía y Okebón. Para el resto de las empresas, dichas estimaciones no arrojan coeficientes estadísticamente significativos, lo que sugiere que Arcor habría subido el precio de sus productos de manera similar a la mayoría de las empresas.

La estimación mediante MCG sugiere que los precios de las galletitas de frutilla son las únicos que parecen haber experimentado aumentos significativamente menores a los observados en los precios de las galletitas de chocolate (categoría base). La estimación del modelo con EA, en cambio, no presenta coeficientes significativos ni para las galletitas de frutilla ni para las de otros sabores, lo que puede interpretarse como un indicio de que no existe una conexión sistemática entre el sabor de las galletitas y los aumentos experimentados por sus precios. Una vez más la conclusión depende de cuál de las especificaciones sea la más adecuada. 
De acuerdo a la primera estimación mediante MCG, las galletitas de agua, las obleas y las rellenas parecen haber experimentado aumentos de precios en mayor medida que las crackers (categoría base). Los precios de las galletitas integrales, por otra parte, muestran una tendencia a haberse incrementado en menor medida que los precios de los productos del ya mencionado grupo de referencia. Sin embargo, los resultados de la segunda estimación realizada mediante MCG, a diferencia de los resultados de la primera, sugieren que las galletitas rellenas y las integrales no han experimentado aumentos de precios significativamente distintos a los observados en las galletitas de tipo crackers. La estimación con EA, por su parte, ni siquiera parece sugerir que el tipo de las galletitas sea una variable relevante a la hora de describir en qué medida aumentaron sus precios durante el período considerado.

Las variaciones en el tipo de cambio parecen guardar una relación inversa con las variaciones en los precios de los paquetes de galletitas, es decir, parece que cuanto más se acelera la variación del tipo de cambio menor es el aumento en los precios de las galletitas. Ello podría deberse a una baja transmisión del tipo de cambio al precio del bien final, evento detectado por mucha literatura económica de Exchange Rate Pass-Through (ERPT), con la consiguiente reducción en el mark-up de las firmas (Delatte \& López-Villavicencio, 2012).

Los valores estimados para los coeficientes asociados a las variables dicotómicas semanales son negativos. Esto parece mostrar en los precios de las galletitas una tendencia a aumentar en mayor medida durante la cuarta semana de cada mes (categoría base). Sin embargo, debe advertirse que la estimación con EA arroja para la variable de la tercera semana un coeficiente muy pequeño, el cual no resulta significativo si se toma un $p$-valor menor o igual al 10\%. Quizá los aumentos que se practican en la cuarta semana no sean en realidad cuantitativamente muy diferentes de los que se llevan a cabo en la tercera.

Las variables dicotómicas anuales también parecen ser significativas. Todas están asociadas a coeficientes cuyos valores estimados son negativos, lo que sugiere que en el 2015 (año asociado a la variable dicotómica omitida) se produjeron mayores aumentos de precios que en el resto del período considerado.

El coeficiente asociado a las variaciones en el precio de la harina de trigo llama la atención. Como este bien es un insumo para la producción de galletitas, se esperaba observar una relación positiva entre las variaciones porcentuales de su precio y las variaciones porcentuales de los precios de las galletitas. Sin embargo, la segunda estimación mediante MCG y la del modelo con EA arrojan coeficientes de signo negativo. Este resultado implicaría que la inflación de las galletitas disminuye a medida que aumenta la inflación de la harina, lo que debe ser explicado de alguna forma. Quizás la forma de modelizar (con datos de panel) o la ausencia de rezagos en la modelización hayan afectado a la forma de capturar la relación entre la variación del costo del insumo y la variación del precio del bien. Asimismo, se debe recordar que se utilizó el precio minorista y no su contraparte mayorista, siendo esta última otra posible explicación al fenómeno. Puede ocurrir, por ejemplo, que el mercado mayorista al abastecer a los productores desabastezca a los consumidores, lo que provocaría que un exceso de oferta mayorista (precio bajo) determina una escasez de oferta en el mercado minorista (precio alto), el cual es el dato procesado aquí. Entonces, bajo este supuesto, un aumento en los precios observados en el mercado minorista podría tener un correlato de precios a la baja en el mercado mayorista, que es efectivamente el insumo del sector.

Por otra parte, los coeficientes que relacionan las variaciones porcentuales de los precios de otros insumos, como los huevos, la leche y los combustibles, con las de los precios de las galletitas registran valores positivos. Estos resultados sí coinciden con los esperados.

En la Tabla 3, por su parte, se reestima el modelo tomando al 2016 como año de referencia, cambio que se realizó considerando que el 2015 no está completo, es decir, que las observaciones utilizadas no cubren todas las semanas de este último año. La tabla en cuestión presenta dos estimaciones con MCG, en la primera de las cuales se ha sustituido la variable que captaba la variación semanal en el precio de compra del dólar por una variable que capta el desvío estándar intrasemanal de 
dicho precio, en tanto que en la segunda se ha sustituido la misma variable por el coeficiente de asimetría del precio de compra del dólar.

Tabla 3. Estimaciones de modelos de datos de panel (continuación).

\begin{tabular}{|c|c|c|}
\hline & MCG (4) & MCG (5) \\
\hline Variables & $P_{i t}$ & $P_{i t}$ \\
\hline \multirow[t]{2}{*}{$\mathrm{IHH}$} & $5.94 \mathrm{e}-08$ & $5.94 \mathrm{e}-08$ \\
\hline & $(3.51 \mathrm{e}-07)$ & $(3.51 \mathrm{e}-07)$ \\
\hline \multirow[t]{2}{*}{ Peso } & 0.000139 & 0.000139 \\
\hline & $(0.000265)$ & $(0.000265)$ \\
\hline \multirow[t]{2}{*}{ Empresa $=2$, Bagley } & -0.000583 & -0.000583 \\
\hline & $(0.000970)$ & $(0.000970)$ \\
\hline \multirow[t]{2}{*}{ Empresa $=3$, Gold Mundo } & -0.00296 & -0.00296 \\
\hline & $(0.00304)$ & $(0.00304)$ \\
\hline \multirow[t]{2}{*}{ Empresa $=4$, Granix } & -0.00145 & -0.00145 \\
\hline & $(0.00162)$ & $(0.00162)$ \\
\hline \multirow[t]{2}{*}{ Empresa $=5$, GreatValue } & -0.00297 & -0.00297 \\
\hline & $(0.00203)$ & $(0.00203)$ \\
\hline \multirow[t]{2}{*}{ Empresa $=6$, Kapac } & -0.00378 & -0.00378 \\
\hline & $(0.00259)$ & $(0.00259)$ \\
\hline \multirow[t]{2}{*}{ Empresa $=7$, Lía } & $-0.00254 *$ & $-0.00254^{*}$ \\
\hline & $(0.00138)$ & $(0.00138)$ \\
\hline \multirow[t]{2}{*}{ Empresa $=8$, Mondelez } & -0.00102 & -0.00102 \\
\hline & $(0.00106)$ & $(0.00106)$ \\
\hline \multirow[t]{2}{*}{ Empresa = 9, Okebón } & -0.00226 & -0.00226 \\
\hline & $(0.00143)$ & $(0.00143)$ \\
\hline \multirow[t]{2}{*}{ Empresa $=10$, Otro } & -0.00158 & -0.00158 \\
\hline & $(0.00140)$ & $(0.00140)$ \\
\hline \multirow[t]{2}{*}{ Empresa $=11$, Pepsi } & -0.000714 & -0.000714 \\
\hline & $(0.00160)$ & $(0.00160)$ \\
\hline \multirow[t]{2}{*}{ Empresa $=12$, Santa María } & -0.00297 & -0.00297 \\
\hline & $(0.00259)$ & $(0.00259)$ \\
\hline \multirow[t]{2}{*}{ Empresa $=13$, Tía Maruca } & $6.58 \mathrm{e}-05$ & $6.58 \mathrm{e}-05$ \\
\hline & $(0.00306)$ & $(0.00306)$ \\
\hline \multirow[t]{2}{*}{ Empresa $=14$, Valente } & 0.000734 & 0.000734 \\
\hline & $(0.00315)$ & $(0.00315)$ \\
\hline \multirow[t]{2}{*}{ Empresa $=15$, Vea } & -0.00169 & -0.00169 \\
\hline & $(0.00312)$ & $(0.00312)$ \\
\hline \multirow[t]{2}{*}{ Feature $=2$, frutilla } & -0.00117 & -0.00117 \\
\hline & $(0.00115)$ & $(0.00115)$ \\
\hline \multirow[t]{2}{*}{ Feature $=3$, otros } & -0.000113 & -0.000113 \\
\hline & $(0.000741)$ & $(0.000741)$ \\
\hline \multirow[t]{2}{*}{ Feature $=4$, semillas } & -0.00123 & -0.00123 \\
\hline & $(0.00215)$ & $(0.00215)$ \\
\hline \multirow[t]{2}{*}{ Type $=2$, De agua } & 0.00215 & 0.00215 \\
\hline & $(0.00249)$ & $(0.00249)$ \\
\hline \multirow[t]{2}{*}{ Type $=3$, Integrales } & -0.000847 & -0.000847 \\
\hline & $(0.00264)$ & $(0.00264)$ \\
\hline \multirow[t]{2}{*}{ Type $=4$, Marineras } & -0.000467 & -0.000467 \\
\hline & $(0.00291)$ & $(0.00291)$ \\
\hline Type $=5$, Obleas & 0.00361 & 0.00361 \\
\hline & $(0.00297)$ & $(0.00297)$ \\
\hline Type $=6$, Rellenas & 0.000223 & 0.000223 \\
\hline & $(0.00251)$ & $(0.00251)$ \\
\hline Type $=7$, Rosquitas & -0.00273 & -0.00273 \\
\hline
\end{tabular}


volatilidad en el mercado cambiario parece corresponderle una menor reducción en los precios de las galletitas o un mayor aumento en los mismos.

El análisis de los coeficientes que acompañan a las variables dicotómicas semanales conduce a los mismos resultados que los obtenidos mediante la estimación EA: sólo son significativos los efectos asociados a las dos primeras semanas, y los coeficientes que los representan son negativos, lo que se interpreta como que en las dos primeras semanas de cada mes se suelen observar variaciones de precios menores a las que se observan en la cuarta semana de cada mes.

Por otra parte, la única variable anual significativa en la Tabla 3 es la correspondiente al año 2018 en el modelo que usa el coeficiente de asimetría del precio del dólar como proxy de la volatilidad cambiaria. Este resultado sugiere que los precios de las galletitas generalmente aumentaron mucho más durante el 2018 que durante el 2016, lo que no es comparable con los resultados de las tres primeras estimaciones debido al cambio de año base.

Los efectos de las variaciones en los precios de los insumos identificados, de acuerdo a las últimas dos estimaciones, son estadísticamente significativos. Este resultado no contradice a los observados en la Tabla 2. Los signos de los coeficientes estimados también coinciden, suscitando una vez más la pregunta de cómo explicar la relación negativa entre las variaciones en el precio de la harina y las de los precios de las galletitas. Esta pregunta quedará abierta, dejando como posibles respuestas las sugeridas al analizar los coeficientes de la Tabla 2.

La primera conclusión importante que surge de este análisis es que los resultados varían según qué método de estimación se haya empleado. Por un lado, las primeras dos estimaciones realizadas mediante MCG sugieren que la tasa a la cual varían los precios de las galletitas debe estar ligada, de algún modo u otro, a prácticamente todos los factores considerados: el grado de concentración de la oferta, el peso de los paquetes, la empresa oferente, el sabor del producto, el tipo de galletitas, el tipo de cambio, el número de semana, el año y los precios de los insumos. Por otro lado, la estimación realizada con EA sugiere que deben tenerse en cuenta todos los factores mencionados excepto el grado de concentración de la oferta, el peso de los paquetes, el sabor y el tipo de las galletitas. La penúltima estimación con MCG sugiere tener en cuenta sólo la volatilidad del mercado cambiario, el número de semana y los precios de los insumos, con el matiz de que hay una empresa que estaría subiendo los precios en menor medida. Finalmente, de la última estimación se desprende la misma sugerencia, pero con el agregado de que también debería considerarse el año de cada observación como variable explicativa.

\section{Conclusiones.}

Este trabajo presenta evidencia de la relación entre la evolución de precios semanal de paquetes de galletitas con diversos determinantes a través de un modelo de datos de panel. Se encuentra que el tamaño de mercado muestra una asociación estadística significativa con las tasas de variación de precios más altas, así como también que las galletitas con composición basada en chocolate aumentaron más aceleradamente de precios. En ese sentido, las galletitas de agua, las obleas y las rellenas han aumentado más aceleradamente que los precios de las crackers en el mercado argentino.

Asimismo, se observa un efecto semanal que destaca que las alzas de la cuarta semana son mayores que las semanas precedentes mientras que, en términos de efectos anuales, el 2015 se perfila como un período con grandes alzas.

En términos de insumos, se ha tomado como proxies la variación de los precios minoristas de huevos, leche y combustibles los cuales mantienen los signos esperados, contrario a lo que sucede con la harina de trigo. Esto último podría deberse a una estructura particular de la oferta de la harina dentro 
del mercado interno que disocie el precio de la harina mayorista de su contraparte minorista, siendo esta última el dato tomado para la estimación. Los otros insumos presentan los signos esperados.

Dentro del mercado cambiario, un indicador de inestabilidad del mismo (el coeficiente de asimetría de las variaciones del precio de compra del dólar) está asociado positivamente con las variaciones de precios de las galletitas en uno de los modelos estimados. Todos estos resultados muestran en definitiva que la fijación de precios semana a semana en esta categoría de productos es ágil: los productores responden rápidamente al contexto del mercado en el muy corto plazo. La inestabilidad macroeconómica del período sin dudas ha jugado un rol.

Como trabajo a futuro se pretende explorar la causalidad colapsando por marcas y por rango de peso de paquetes, para ver comportamientos oligopólicos. En ese sentido, serán exploradas en profundidad las interrelaciones entre productos de distintas marcas, así como entre productos de la misma marca que compitan por los mismos segmentos de un mercado.

\section{Agradecimientos}

Este trabajo ha sido financiado por el Proyecto de Grupo de Investigación 24/E159 de la Universidad Nacional del Sur.

\section{Referencias}

Anders, S., \& Ahmad, W. (2011, agosto). Private label and national brand pricing and promotional strategies in health differentiated product categories: Canadian evidence. EAAE 2011 Congress: Change and Uncertainty, ETH Zurich. Zurich, Suiza.

Arellano, M., \& Bond, S. (1991). Some tests of specification for panel data: Monte Carlo evidence and an application to employment equations. The Review of Economic Studies, 58(2), 277-97. DOI: $10.2307 / 2297968$.

Baltagi, B. H. (2012). Econometric Analysis of Panel Data. New York: Wiley \& Sons.

Beets, M.W., Weaver, R.G., Tilley, F., Turner-McGrievy, G., Huberty, J., Ward, D. S., \& Freedman, D. A. (2015). Salty or sweet? Nutritional quality, consumption, and cost of snacks served in afterschool programs. Journal of School Health, 85(2), 118-124. DOI: 10.1111/josh. 12224.

Blundell, R., \& Bond, S. (1998). Initial conditions and moment restrictions in dynamic panel data models. Journal of Econometrics, 87(1), 115-143. DOI: 10.1016/S0304-4076(98)00009-8.

Borg, E.A. (2013). Interpreting Brand Development as Entrepreneurship - The Role of Brand Strategies. GSTF Journal on Business Review (GBR), 2 (4). DOI: 10.5176/2010-4804_2.4.266

Burns, C., Cook, K., \& Mavoa, H. (2013). Role of expendable income and price in food choice by low income families. Appetite, 71, 209-217. DOI: 10.1016/j.appet.2013.08.018.

Byrd-Bredbenner, C., Johnson, M., Quick, V.M., Walsh, J., Greene, G.W., Hoerr, S., Colby, S.M., Kattelmann, K.K., Phillips, B.W., Kidd, T., \& Horacek, T.M. (2012). Sweet and salty: An assessment of the snacks and beverages sold in vending machines on US post-secondary institution campuses. Appetite 58, 1143-1151. DOI: 10.1016/j.appet.2012.02.055. 
Cameron, A. C., \& Trivedi, P. K. (2009). Microeconometrics using Stata. Volumen 5. College Station, TX: Stata press.

Cavallo, A. (2013). Online and official price indexes: Measuring Argentina's inflation. Journal of Monetary Economics, 60(2), 152-165. DOI: 10.2139/ssrn.1906704.

Chadwick, M., \& Bastan, M. (2017). News impact for Turkish food prices. Central Bank Review, 17(2), 55-76. DOI: 10.1016/j.cbrev.2017.05.001.

Coloma, G. (2007). The Arcor/Bagley merger and the Argentine biscuit market: Price increases vs. cost reductions". The Icfai Journal of Mergers \& Acquisitions, 4 (2), 14-28.

Clarín $(2011,13,11)$. El consumo de galletitas está entre los más altos del mundo. Descargado el 16/07/2018 de https://www.clarin.com/empresas_y_negocios/consumo-galletitas-altosmundo_0_H1nlt25hwmg.html

Delatte, A.-L., \& López-Villavicencio, A. (2012). Asymmetric exchange rate pass-through: Evidence from major countries. Journal of Macroeconomics, 34(3), 833-844. DOI: 10.1016/j.jmacro.2012.03.003.

Depodwin, H.J., \& Selden, R.T. (1963). Business pricing policies and inflation. Journal of Political Economy, 71(2), 116-127. DOI: 10.1086/258748.

Drenik, A., \& Perez, D.J. (2020). Price setting under uncertainty about inflation. Journal of Monetary Economics, 116, 23-38. DOI: 10.1016/j.jmoneco.2019.10.004.

French, M. (2017). Modernity in British advertising: selling cocoa and chocolate in the 1930s. Journal of Historical Research in Marketing, 9(4), 451-466. DOI: 10.1108/JHRM-05-2017-0015.

Greene, W. H. (2012). Econometric Analysis. Upper Saddle River, NJ: Prentice Hall.

IRi (2018). How America eats: 2018 state of the snack food industry. Descargado de https://www.iriworldwide.com/IRI/media/Library/2018-State-of-the-Snack-Food-Industry _03_27_18_Webinar_F.pdf

Hisano, A. (2017). Cellophane, the new visuality, and the creation of self-service food retailing. Harvard Business School Working Paper No. 17-106. DOI: 10.2139/ssrn.2973544.

Jones, J.C.H., \& Laudadio, L. (1990). Price rigidity, inflation and market concentration: Some Canadian evidence from the 1970s. Applied Economics, 22(12), 1625-1634. DOI: $10.1080 / 00036849000000069$.

Lustgarten, S. (1975a). Industrial concentration and inflation. Washington, DC: American Enterprise Institute.

Lustgarten, S. (1975b). Administered inflation: A reappraisal. Economic Inquiry, 13(2), 191-206. DOI: 10.1111/j.1465-7295.1975.tb00987.x.

Machado, P.P., Claro, R.M., Canella, D.S., Sarti, F.M., \& Levy, R.B. (2017). Price and convenience: The influence of supermarkets on consumption of ultra-processed foods and beverages in Brazil. Appetite, 116(1), 381-388. DOI: 10.1016/j.appet.2017.05.027.

Martínez, C., Santa Cruz, M.J., Hough, G., \& Vega, M.J. (2002). Preference mapping of cracker type biscuits. Food Quality and Preference, 13(7-8), 535-544. DOI: 10.1016/S0950-3293(02)00087-3. 
Mehra, P. (2017). Fast moving consumer goods (FMCG) industry in India and its key approaches. International Journal of Engineering Technology Science and Research, 4(8), 575-580.

Miranda-Zanetti, M., Delbianco, F., \& Tohmé, F. (2019). Tampering with inflation data: A Benford law-based analysis of national statistics in Argentina. Physica A: Statistical Mechanics and its Applications, 525, 761-770. DOI: 10.1016/j.physa.2019.04.042.

Nandeshwar, N.S., Ganvir, B.N., Suryawanshi, S.N., \& Bagade, N.T. (2017). Value addition in wheat - biscuit, buns, toast. International Research Journal of Agricultural Economics and Statistics, 8(1), 112-116. DOI: $10.15740 /$ has/irjaes/8.1/112-116.

O’Donnell, C.J., Griffith, G.R., Nightingale, J.J., \& Piggott, R.R. (2007). Testing for market power in the Australian grains and oilseeds industries. Agribusiness, 23(3), 349-376. DOI: 10.1002/agr.20128.

Perekhozhuk, O., Grings, M., Teuber, R., \& Glauben, T. (2016). Approaches and methods for the econometric analysis of market power: A survey and empirical comparison. Journal of Economic Surveys, 31(1), 303-325. DOI: 10.1111/joes.12141.

Rai, B.S., Shukla, S., Kishor, K., Singh, H., \& Dey, S. (2017). Studies on cost of production for value added prepared mixed flour biscuit. International Journal of Chemical Studies, 5(4), 1904-1905. Descargado de http://www.chemijournal.com/archives/?year=2017\&vol=5\& issue $=4 \&$ ArticleId $=899$

Ramli, N.S. (2017). A review of marketing strategies from the European Chocolate Industry. Journal of Global Entrepreneurship Research, 7(10), 1-17. DOI: 10.1186/s40497-017-0068-0.

Santlofer, J. (2007). Hard as the hubs of Hell. Food, Culture \& Society, 10(2), 191-209. DOI: $10.2752 / 155280107 \mathrm{X} 211412$.

Sosa-Escudero, W., \& Bera, A. K. (2008). Tests for unbalanced error-components models under local misspecification. The Stata Journal, 8(1), 68-78. DOI: 10.1177/1536867X0800800105.

Symeonidis, G. (2017). Does product market competition increase strike activity? Evidence from the UK. European Economic Review, 97, 42-56. DOI: 10.1016/j.euroecorev.2017.05.008.

Tweede, D. (2012). The birth of modern packaging. Journal of Historical Research in Marketing, 4(2), 245-272. DOI 10.1108/17557501211224449.

Uriarte, J.I., González Ramírez Muñoz de Toro, G.R., \& Larrosa, J.M.C. (2019). Web scraping based online consumer price index: the 'IPC Online' case. Journal of Economic and Social Measurement, 44(2-3), 141-159. DOI: 10.3233/JEM-190464.

Vergura, D. T., \& Luceri, B. (2017). Product packaging and consumers' emotional response. Does spatial representation influence product evaluation and choice? Journal of Consumer Marketing, 35(2), 218-227. DOI: 10.1108/JCM-12-2016-2021.

Weiss, L.W. (1966). Business pricing policies and inflation reconsidered. Journal of Political Economy, 74(2), 177-187. DOI: 10.1086/259134.

Williams, R.L., \& Williams, H.A. (2017). Vintage marketing differentiation: The origins of marketing and branding strategies. New York: Palgrave Macmillan. DOI 10.1057/978-1-137-38721-9.

Wilson, N.L.W. (2011). How the cookie crumbles: A case study of gluten-free cookies and random utility. American Journal of Agricultural Economics, 94(2), 576-582. DOI: 10.1093/ajae/aar081. 
Yang, F., Bekkers, E., Brockmeier, M., \& Francois, J. (2015). Food price pass-through and the role of domestic margin services. Journal of Agricultural Economics, 66(3), 796-811. DOI: 10.1111/14779552.12110 .

Yordon, W. J. (1961). Industrial concentration and price flexibility in inflation: Price response rates in fourteen industries, 1947-1958. The Review of Economics and Statistics, 43(3), 287-294. DOI: $10.2307 / 1927292$.

Zaleski, P. A. (1992). Industry concentration and the transmission of cost-push inflation: Evidence from the 1974 OPEC oil crisis. Journal of Economics and Business, 44 (2), 135-141. DOI: 10.1016/01486195(92)90012-Y.

\section{Apéndice}

Tabla 4. Estadística descriptiva de las variables.

\begin{tabular}{|c|c|c|c|c|c|c|c|c|}
\hline Variable & Media & $\begin{array}{c}\text { Desvío } \\
\text { Estándar }\end{array}$ & Asimetría & Curtosis & Máximo & Mínimo & Moda & Mediana \\
\hline producto/marca1 & $0,52 \%$ & $2,46 \%$ & 5,01 & 27,42 & $18,69 \%$ & $-2,62 \%$ & $0,00 \%$ & $0,00 \%$ \\
\hline producto/marca2 & $0,05 \%$ & $0,67 \%$ & 12,17 & 148,00 & $8,11 \%$ & $0,00 \%$ & $0,00 \%$ & $0,00 \%$ \\
\hline producto/marca3 & $0,05 \%$ & $0,67 \%$ & 12,17 & 148,00 & $8,11 \%$ & $0,00 \%$ & $0,00 \%$ & $0,00 \%$ \\
\hline producto/marca4 & $0,07 \%$ & $0,89 \%$ & 12,17 & 148,00 & $10,81 \%$ & $0,00 \%$ & $0,00 \%$ & $0,00 \%$ \\
\hline producto/marca5 & $0,19 \%$ & $2,00 \%$ & 4,41 & 38,43 & $15,16 \%$ & $-10,12 \%$ & $0,00 \%$ & $0,00 \%$ \\
\hline producto/marca6 & $0,24 \%$ & $2,08 \%$ & 8,58 & 73,06 & $19,19 \%$ & $0,00 \%$ & $0,00 \%$ & $0,00 \%$ \\
\hline producto/marca7 & $0,06 \%$ & $0,68 \%$ & 12,17 & 148,00 & $8,22 \%$ & $0,00 \%$ & $0,00 \%$ & $0,00 \%$ \\
\hline producto/marca8 & $0,38 \%$ & $2,20 \%$ & 6,29 & 41,82 & $18,24 \%$ & $0,00 \%$ & $0,00 \%$ & $0,00 \%$ \\
\hline producto/marca9 & $0,00 \%$ & $0,00 \%$ & & & $0,00 \%$ & $0,00 \%$ & $0,00 \%$ & $0,00 \%$ \\
\hline producto/marca10 & $0,06 \%$ & $0,68 \%$ & 12,17 & 148,00 & $8,22 \%$ & $0,00 \%$ & $0,00 \%$ & $0,00 \%$ \\
\hline producto/marca11 & $0,06 \%$ & $0,68 \%$ & 12,17 & 148,00 & $8,22 \%$ & $0,00 \%$ & $0,00 \%$ & $0,00 \%$ \\
\hline producto/marca12 & $0,06 \%$ & $0,75 \%$ & 12,17 & 148,00 & $9,12 \%$ & $0,00 \%$ & $0,00 \%$ & $0,00 \%$ \\
\hline producto/marca 13 & $0,32 \%$ & $3,94 \%$ & 3,15 & 57,37 & $35,52 \%$ & $-26,21 \%$ & $0,00 \%$ & $0,00 \%$ \\
\hline producto/marca14 & $0,06 \%$ & $0,73 \%$ & 12,17 & 148,00 & $8,93 \%$ & $0,00 \%$ & $0,00 \%$ & $0,00 \%$ \\
\hline producto/marca15 & $0,25 \%$ & $1,54 \%$ & 6,25 & 39,06 & $12,03 \%$ & $0,00 \%$ & $0,00 \%$ & $0,00 \%$ \\
\hline producto/marca16 & $0,03 \%$ & $0,41 \%$ & 12,17 & 148,00 & $4,95 \%$ & $0,00 \%$ & $0,00 \%$ & $0,00 \%$ \\
\hline producto/marca17 & $0,03 \%$ & $0,40 \%$ & 12,17 & 148,00 & $4,89 \%$ & $0,00 \%$ & $0,00 \%$ & $0,00 \%$ \\
\hline producto/marca 18 & $0,38 \%$ & $3,60 \%$ & 11,36 & 133,71 & $42,86 \%$ & $0,00 \%$ & $0,00 \%$ & $0,00 \%$ \\
\hline producto/marca19 & $0,09 \%$ & $1,07 \%$ & 12,17 & 148,00 & $12,99 \%$ & $0,00 \%$ & $0,00 \%$ & $0,00 \%$ \\
\hline producto/marca 20 & $0,20 \%$ & $1,72 \%$ & 8,57 & 72,64 & $15,77 \%$ & $0,00 \%$ & $0,00 \%$ & $0,00 \%$ \\
\hline producto/marca21 & $0,72 \%$ & $5,09 \%$ & 8,67 & 82,82 & $53,41 \%$ & $0,00 \%$ & $0,00 \%$ & $0,00 \%$ \\
\hline producto/marca22 & $0,58 \%$ & $5,52 \%$ & 5,60 & 49,29 & $42,86 \%$ & $-25,00 \%$ & $0,00 \%$ & $0,00 \%$ \\
\hline producto/marca 23 & $0,21 \%$ & $1,24 \%$ & 5,90 & 33,33 & $7,83 \%$ & $0,00 \%$ & $0,00 \%$ & $0,00 \%$ \\
\hline producto/marca24 & $1,56 \%$ & $7,53 \%$ & 4,24 & 23,76 & $48,15 \%$ & $-25,03 \%$ & $0,00 \%$ & $0,00 \%$ \\
\hline producto/marca 25 & $0,06 \%$ & $0,71 \%$ & 12,17 & 148,00 & $8,68 \%$ & $0,00 \%$ & $0,00 \%$ & $0,00 \%$ \\
\hline producto/marca26 & $0,05 \%$ & $0,62 \%$ & 12,17 & 148,00 & $7,52 \%$ & $0,00 \%$ & $0,00 \%$ & $0,00 \%$ \\
\hline producto/marca 27 & $0,08 \%$ & $0,96 \%$ & 12,17 & 148,00 & $11,67 \%$ & $0,00 \%$ & $0,00 \%$ & $0,00 \%$ \\
\hline producto/marca28 & $0,05 \%$ & $0,44 \%$ & 8,51 & 71,44 & $3,77 \%$ & $0,00 \%$ & $0,00 \%$ & $0,00 \%$ \\
\hline producto/marca29 & $0,06 \%$ & $0,71 \%$ & 12,17 & 148,00 & $8,68 \%$ & $0,00 \%$ & $0,00 \%$ & $0,00 \%$ \\
\hline producto/marca30 & $0,08 \%$ & $0,96 \%$ & 12,17 & 148,00 & $11,67 \%$ & $0,00 \%$ & $0,00 \%$ & $0,00 \%$ \\
\hline producto/marca31 & $0,05 \%$ & $0,63 \%$ & 12,17 & 148,00 & $7,69 \%$ & $0,00 \%$ & $0,00 \%$ & $0,00 \%$ \\
\hline producto/marca32 & $0,05 \%$ & $0,62 \%$ & 12,17 & 148,00 & $7,59 \%$ & $0,00 \%$ & $0,00 \%$ & $0,00 \%$ \\
\hline producto/marca33 & $-0,12 \%$ & $5,08 \%$ & 1,32 & 50,23 & $42,84 \%$ & $-29,99 \%$ & $0,00 \%$ & $0,00 \%$ \\
\hline producto/marca34 & $0,74 \%$ & $6,66 \%$ & 5,86 & 54,52 & $59,56 \%$ & $-29,97 \%$ & $0,00 \%$ & $0,00 \%$ \\
\hline producto/marca35 & $0,05 \%$ & $0,63 \%$ & 12,17 & 148,00 & $7,69 \%$ & $0,00 \%$ & $0,00 \%$ & $0,00 \%$ \\
\hline
\end{tabular}




\begin{tabular}{|c|c|c|c|c|c|c|c|c|}
\hline producto/marca36 & $0,68 \%$ & $8,39 \%$ & 2,15 & 17,41 & $59,11 \%$ & $-27,39 \%$ & $0,00 \%$ & $0,00 \%$ \\
\hline producto/marca37 & $0,69 \%$ & $3,83 \%$ & 2,18 & 31,90 & $29,44 \%$ & $-22,74 \%$ & $0,00 \%$ & $0,00 \%$ \\
\hline producto/marca38 & $0,59 \%$ & $3,70 \%$ & 2,28 & 36,72 & $29,44 \%$ & $-22,74 \%$ & $0,00 \%$ & $0,00 \%$ \\
\hline producto/marca39 & $0,61 \%$ & $3,70 \%$ & 2,26 & 36,51 & $29,44 \%$ & $-22,74 \%$ & $0,00 \%$ & $0,00 \%$ \\
\hline producto/marca40 & $1,05 \%$ & $8,31 \%$ & 4,11 & 49,30 & $75,65 \%$ & $-43,07 \%$ & $0,00 \%$ & $0,00 \%$ \\
\hline producto/marca41 & $0,07 \%$ & $0,84 \%$ & 12,17 & 148,00 & $10,27 \%$ & $0,00 \%$ & $0,00 \%$ & $0,00 \%$ \\
\hline producto/marca42 & $0,55 \%$ & $4,05 \%$ & 10,59 & 120,49 & $47,08 \%$ & $0,00 \%$ & $0,00 \%$ & $0,00 \%$ \\
\hline producto/marca43 & $0,05 \%$ & $0,59 \%$ & 12,17 & 148,00 & $7,14 \%$ & $0,00 \%$ & $0,00 \%$ & $0,00 \%$ \\
\hline producto/marca44 & $0,03 \%$ & $0,42 \%$ & 12,17 & 148,00 & $5,07 \%$ & $0,00 \%$ & $0,00 \%$ & $0,00 \%$ \\
\hline producto/marca45 & $0,53 \%$ & $5,42 \%$ & 1,79 & 18,07 & $32,07 \%$ & $-24,28 \%$ & $0,00 \%$ & $0,00 \%$ \\
\hline producto/marca46 & $0,64 \%$ & $3,79 \%$ & 2,08 & 17,77 & $23,12 \%$ & $-18,78 \%$ & $0,00 \%$ & $0,00 \%$ \\
\hline producto/marca47 & $0,57 \%$ & $5,41 \%$ & 2,33 & 20,17 & $32,45 \%$ & $-23,73 \%$ & $0,00 \%$ & $0,00 \%$ \\
\hline producto/marca48 & $0,29 \%$ & $1,34 \%$ & 4,95 & 24,43 & $8,35 \%$ & $0,00 \%$ & $0,00 \%$ & $0,00 \%$ \\
\hline producto/marca49 & $-0,21 \%$ & $4,72 \%$ & $-1,28$ & 15,25 & $24,22 \%$ & $-24,28 \%$ & $0,00 \%$ & $0,00 \%$ \\
\hline producto/marca50 & $0,41 \%$ & $3,12 \%$ & 2,11 & 39,44 & $25,13 \%$ & $-20,08 \%$ & $0,00 \%$ & $0,00 \%$ \\
\hline producto/marca51 & $0,51 \%$ & $2,00 \%$ & 4,23 & 18,36 & $13,43 \%$ & $0,00 \%$ & $0,00 \%$ & $0,00 \%$ \\
\hline producto/marca52 & $0,00 \%$ & $0,00 \%$ & & & $0,00 \%$ & $0,00 \%$ & $0,00 \%$ & $0,00 \%$ \\
\hline producto/marca53 & $0,10 \%$ & $1,17 \%$ & 12,17 & 148,00 & $14,29 \%$ & $0,00 \%$ & $0,00 \%$ & $0,00 \%$ \\
\hline producto/marca54 & $0,15 \%$ & $1,09 \%$ & 7,20 & 52,16 & $9,38 \%$ & $0,00 \%$ & $0,00 \%$ & $0,00 \%$ \\
\hline producto/marca55 & $0,81 \%$ & $5,91 \%$ & 8,25 & 70,21 & $56,25 \%$ & $0,00 \%$ & $0,00 \%$ & $0,00 \%$ \\
\hline producto/marca56 & $1,15 \%$ & $6,89 \%$ & 4,49 & 26,93 & $42,86 \%$ & $-24,42 \%$ & $0,00 \%$ & $0,00 \%$ \\
\hline producto/marca57 & $0,89 \%$ & $6,79 \%$ & 8,95 & 83,77 & $70,07 \%$ & $0,00 \%$ & $0,00 \%$ & $0,00 \%$ \\
\hline producto/marca58 & $0,05 \%$ & $0,60 \%$ & 12,17 & 148,00 & $7,29 \%$ & $0,00 \%$ & $0,00 \%$ & $0,00 \%$ \\
\hline producto/marca59 & $0,10 \%$ & $1,17 \%$ & 12,17 & 148,00 & $14,29 \%$ & $0,00 \%$ & $0,00 \%$ & $0,00 \%$ \\
\hline producto/marca60 & $0,31 \%$ & $4,71 \%$ & 2,61 & 17,23 & $28,57 \%$ & $-15,28 \%$ & $0,00 \%$ & $0,00 \%$ \\
\hline producto/marca61 & $0,23 \%$ & $1,85 \%$ & 9,40 & 95,92 & $20,22 \%$ & $0,00 \%$ & $0,00 \%$ & $0,00 \%$ \\
\hline producto/marca62 & $0,19 \%$ & $1,17 \%$ & 5,94 & 33,94 & $7,69 \%$ & $0,00 \%$ & $0,00 \%$ & $0,00 \%$ \\
\hline producto/marca63 & $0,05 \%$ & $0,61 \%$ & 12,17 & 148,00 & $7,43 \%$ & $0,00 \%$ & $0,00 \%$ & $0,00 \%$ \\
\hline producto/marca64 & $0,42 \%$ & $6,15 \%$ & 2,82 & 29,83 & $45,48 \%$ & $-31,26 \%$ & $0,00 \%$ & $0,00 \%$ \\
\hline producto/marca65 & $0,15 \%$ & $1,07 \%$ & 7,73 & 61,04 & $8,88 \%$ & $0,00 \%$ & $0,00 \%$ & $0,00 \%$ \\
\hline producto/marca66 & $0,61 \%$ & $5,67 \%$ & 4,56 & 43,52 & $42,86 \%$ & $-29,26 \%$ & $0,00 \%$ & $0,00 \%$ \\
\hline producto/marca67 & $0,70 \%$ & $5,06 \%$ & 8,04 & 65,44 & $42,86 \%$ & $0,00 \%$ & $0,00 \%$ & $0,00 \%$ \\
\hline producto/marca68 & $0,45 \%$ & $3,69 \%$ & 10,66 & 120,94 & $42,86 \%$ & $0,00 \%$ & $0,00 \%$ & $0,00 \%$ \\
\hline producto/marca69 & $0,24 \%$ & $1,47 \%$ & 6,07 & 36,03 & $10,67 \%$ & $0,00 \%$ & $0,00 \%$ & $0,00 \%$ \\
\hline producto/marca70 & $0,45 \%$ & $2,39 \%$ & 3,62 & 19,70 & $15,50 \%$ & $-9,05 \%$ & $0,00 \%$ & $0,00 \%$ \\
\hline producto/marca71 & $0,50 \%$ & $2,39 \%$ & 3,45 & 18,34 & $15,94 \%$ & $-8,90 \%$ & $0,00 \%$ & $0,00 \%$ \\
\hline producto/marca 72 & $0,65 \%$ & $2,64 \%$ & 3,08 & 14,54 & $15,87 \%$ & $-9,47 \%$ & $0,00 \%$ & $0,00 \%$ \\
\hline producto/marca 73 & $0,98 \%$ & $5,71 \%$ & 1,30 & 10,73 & $33,49 \%$ & $-24,91 \%$ & $0,00 \%$ & $0,00 \%$ \\
\hline producto/marca74 & $0,66 \%$ & $4,88 \%$ & $-0,46$ & 11,32 & $20,05 \%$ & $-27,04 \%$ & $0,00 \%$ & $0,00 \%$ \\
\hline producto/marca75 & $0,55 \%$ & $2,27 \%$ & 4,78 & 24,04 & $16,06 \%$ & $0,00 \%$ & $0,00 \%$ & $0,00 \%$ \\
\hline producto/marca76 & $0,16 \%$ & $1,07 \%$ & 7,33 & 55,35 & $8,71 \%$ & $0,00 \%$ & $0,00 \%$ & $0,00 \%$ \\
\hline producto/marca77 & $0,21 \%$ & $1,47 \%$ & 7,00 & 48,33 & $11,80 \%$ & $0,00 \%$ & $0,00 \%$ & $0,00 \%$ \\
\hline producto/marca78 & $0,28 \%$ & $1,51 \%$ & 6,52 & 44,83 & $11,99 \%$ & $0,00 \%$ & $0,00 \%$ & $0,00 \%$ \\
\hline producto/marca79 & $0,67 \%$ & $5,91 \%$ & 2,63 & 18,82 & $40,75 \%$ & $-21,63 \%$ & $0,00 \%$ & $0,00 \%$ \\
\hline producto/marca 80 & $0,46 \%$ & $3,88 \%$ & 3,26 & 43,69 & $33,20 \%$ & $-22,69 \%$ & $0,00 \%$ & $0,00 \%$ \\
\hline producto/marca 81 & $0,27 \%$ & $1,52 \%$ & 5,76 & 32,07 & $9,75 \%$ & $0,00 \%$ & $0,00 \%$ & $0,00 \%$ \\
\hline producto/marca 82 & $0,18 \%$ & $1,38 \%$ & 5,54 & 36,02 & $9,47 \%$ & $-4,41 \%$ & $0,00 \%$ & $0,00 \%$ \\
\hline producto/marca 84 & $0,12 \%$ & $4,14 \%$ & 1,74 & 44,18 & $34,07 \%$ & $-25,41 \%$ & $0,00 \%$ & $0,00 \%$ \\
\hline producto/marca 85 & $0,08 \%$ & $0,91 \%$ & 12,17 & 148,00 & $11,11 \%$ & $0,00 \%$ & $0,00 \%$ & $0,00 \%$ \\
\hline producto/marca 86 & $0,10 \%$ & $1,17 \%$ & 12,17 & 148,00 & $14,29 \%$ & $0,00 \%$ & $0,00 \%$ & $0,00 \%$ \\
\hline producto/marca 88 & $0,12 \%$ & $1,44 \%$ & 12,17 & 148,00 & $17,50 \%$ & $0,00 \%$ & $0,00 \%$ & $0,00 \%$ \\
\hline producto/marca 89 & $0,83 \%$ & $1,82 \%$ & $-0,96$ & 8,75 & $7,16 \%$ & $-9,92 \%$ & $3,22 \%$ & $0,61 \%$ \\
\hline producto/marca90 & $0,20 \%$ & $1,40 \%$ & 7,82 & 64,50 & $13,42 \%$ & $0,00 \%$ & $0,00 \%$ & $0,00 \%$ \\
\hline producto/marca91 & $0,72 \%$ & $6,31 \%$ & 1,06 & 5,92 & $25,08 \%$ & $-17,52 \%$ & $0,00 \%$ & $0,00 \%$ \\
\hline producto/marca92 & $0,43 \%$ & $6,39 \%$ & 4,65 & 38,47 & $52,66 \%$ & $-19,35 \%$ & $0,00 \%$ & $0,00 \%$ \\
\hline producto/marca93 & $0,62 \%$ & $4,15 \%$ & 4,60 & 41,61 & $36,00 \%$ & $-19,09 \%$ & $0,00 \%$ & $0,00 \%$ \\
\hline producto/marca94 & $0,36 \%$ & $1,90 \%$ & 3,64 & 18,16 & $10,06 \%$ & $-6,90 \%$ & $0,00 \%$ & $0,00 \%$ \\
\hline producto/marca97 & $1,01 \%$ & $6,93 \%$ & 0,86 & 6,10 & $27,91 \%$ & $-21,82 \%$ & $0,00 \%$ & $0,00 \%$ \\
\hline producto/marca98 & $1,11 \%$ & $4,53 \%$ & 5,72 & 39,96 & $39,90 \%$ & $0,00 \%$ & $0,00 \%$ & $0,00 \%$ \\
\hline producto/marca99 & $0,35 \%$ & $1,56 \%$ & 4,85 & 23,76 & $9,80 \%$ & $0,00 \%$ & $0,00 \%$ & $0,00 \%$ \\
\hline
\end{tabular}




\begin{tabular}{|c|c|c|c|c|c|c|c|c|}
\hline producto/marca100 & $0,61 \%$ & $5,40 \%$ & 7,97 & 85,09 & $57,49 \%$ & $-10,74 \%$ & $0,00 \%$ & $0,00 \%$ \\
\hline producto/marca101 & $0,33 \%$ & $1,80 \%$ & 5,57 & 30,79 & $13,07 \%$ & $0,00 \%$ & $0,00 \%$ & $0,00 \%$ \\
\hline producto/marca102 & $0,26 \%$ & $4,51 \%$ & 2,55 & 20,87 & $27,73 \%$ & $-16,98 \%$ & $0,00 \%$ & $0,00 \%$ \\
\hline producto/marca103 & $-0,20 \%$ & $2,47 \%$ & $-12,17$ & 148,00 & $0,00 \%$ & $-30,00 \%$ & $0,00 \%$ & $0,00 \%$ \\
\hline producto/marca104 & $0,27 \%$ & $8,51 \%$ & 0,89 & 11,29 & $41,48 \%$ & $-30,00 \%$ & $0,00 \%$ & $0,00 \%$ \\
\hline producto/marca105 & $0,70 \%$ & $3,53 \%$ & 1,80 & 8,49 & $14,09 \%$ & $-12,35 \%$ & $0,00 \%$ & $0,00 \%$ \\
\hline producto/marca106 & $0,11 \%$ & $0,70 \%$ & 6,52 & 43,27 & $5,59 \%$ & $0,00 \%$ & $0,00 \%$ & $0,00 \%$ \\
\hline producto/marca107 & $0,16 \%$ & $1,35 \%$ & 8,85 & 79,47 & $13,42 \%$ & $0,00 \%$ & $0,00 \%$ & $0,00 \%$ \\
\hline producto/marca108 & $0,81 \%$ & $6,30 \%$ & 1,45 & 6,98 & $26,65 \%$ & $-17,52 \%$ & $0,00 \%$ & $0,00 \%$ \\
\hline producto/marca109 & $0,23 \%$ & $1,29 \%$ & 6,03 & 36,15 & $9,56 \%$ & $0,00 \%$ & $0,00 \%$ & $0,00 \%$ \\
\hline producto/marca1 10 & $0,44 \%$ & $4,96 \%$ & 0,62 & 8,34 & $18,38 \%$ & $-21,79 \%$ & $0,00 \%$ & $0,00 \%$ \\
\hline producto/marca111 & $-0,67 \%$ & $4,34 \%$ & $-3,28$ & 18,49 & $15,68 \%$ & $-24,88 \%$ & $0,00 \%$ & $0,00 \%$ \\
\hline producto/marca112 & $-0,20 \%$ & $4,32 \%$ & $-2,08$ & 47,80 & $30,57 \%$ & $-30,10 \%$ & $0,00 \%$ & $0,00 \%$ \\
\hline producto/marca1 13 & $-0,27 \%$ & $4,05 \%$ & $-0,17$ & 40,09 & $30,57 \%$ & $-25,67 \%$ & $0,00 \%$ & $0,00 \%$ \\
\hline producto/marca114 & $-0,57 \%$ & $7,01 \%$ & $-0,03$ & 19,52 & $43,06 \%$ & $-30,10 \%$ & $0,00 \%$ & $0,00 \%$ \\
\hline producto/marca115 & $-0,15 \%$ & $6,21 \%$ & 1,11 & 27,68 & $43,06 \%$ & $-30,10 \%$ & $0,00 \%$ & $0,00 \%$ \\
\hline producto/marca1 16 & $0,21 \%$ & $1,00 \%$ & 4,87 & 24,42 & $7,18 \%$ & $0,00 \%$ & $0,00 \%$ & $0,00 \%$ \\
\hline producto/marca117 & $0,00 \%$ & $0,00 \%$ & & & $0,00 \%$ & $0,00 \%$ & $0,00 \%$ & $0,00 \%$ \\
\hline producto/marca1 18 & $0,28 \%$ & $3,00 \%$ & 7,99 & 88,76 & $32,16 \%$ & $-9,13 \%$ & $0,00 \%$ & $0,00 \%$ \\
\hline producto/marca119 & $-0,41 \%$ & $6,02 \%$ & $-2,52$ & 23,66 & $32,16 \%$ & $-35,74 \%$ & $0,00 \%$ & $0,00 \%$ \\
\hline producto/marca120 & $0,15 \%$ & $5,66 \%$ & 1,62 & 40,79 & $45,38 \%$ & $-31,21 \%$ & $0,00 \%$ & $0,00 \%$ \\
\hline producto/marca121 & $0,15 \%$ & $7,14 \%$ & 0,36 & 10,29 & $31,82 \%$ & $-25,73 \%$ & $0,00 \%$ & $0,00 \%$ \\
\hline producto/marca122 & $0,33 \%$ & $5,80 \%$ & 1,56 & 20,45 & $31,82 \%$ & $-25,47 \%$ & $0,00 \%$ & $0,00 \%$ \\
\hline producto/marca 123 & $-0,06 \%$ & $4,14 \%$ & 0,75 & 50,36 & $34,17 \%$ & $-25,47 \%$ & $0,00 \%$ & $0,00 \%$ \\
\hline producto/marca124 & $-0,38 \%$ & $5,02 \%$ & $-2,25$ & 29,09 & $30,57 \%$ & $-30,10 \%$ & $0,00 \%$ & $0,00 \%$ \\
\hline producto/marca125 & $0,21 \%$ & $3,72 \%$ & 2,38 & 49,82 & $32,16 \%$ & $-24,33 \%$ & $0,00 \%$ & $0,00 \%$ \\
\hline producto/marca126 & $0,21 \%$ & $3,72 \%$ & 2,38 & 49,82 & $32,16 \%$ & $-24,33 \%$ & $0,00 \%$ & $0,00 \%$ \\
\hline producto/marca127 & $0,96 \%$ & $6,52 \%$ & 2,82 & 17,52 & $34,77 \%$ & $-25,29 \%$ & $0,00 \%$ & $0,00 \%$ \\
\hline producto/marca 128 & $0,29 \%$ & $1,37 \%$ & 4,90 & 23,70 & $8,38 \%$ & $0,00 \%$ & $0,00 \%$ & $0,00 \%$ \\
\hline producto/marca129 & $0,15 \%$ & $1,07 \%$ & 7,08 & 49,79 & $8,89 \%$ & $0,00 \%$ & $0,00 \%$ & $0,00 \%$ \\
\hline producto/marca130 & $0,33 \%$ & $1,46 \%$ & 4,51 & 19,72 & $8,38 \%$ & $0,00 \%$ & $0,00 \%$ & $0,00 \%$ \\
\hline producto/marca131 & $0,18 \%$ & $1,53 \%$ & 8,51 & 71,44 & $13,19 \%$ & $0,00 \%$ & $0,00 \%$ & $0,00 \%$ \\
\hline producto/marca132 & $0,56 \%$ & $6,11 \%$ & 1,92 & 16,69 & $30,25 \%$ & $-28,78 \%$ & $0,00 \%$ & $0,00 \%$ \\
\hline producto/marca133 & $0,39 \%$ & $5,72 \%$ & 1,40 & 21,95 & $35,66 \%$ & $-26,29 \%$ & $0,00 \%$ & $0,00 \%$ \\
\hline producto/marca134 & $0,30 \%$ & $6,26 \%$ & 0,68 & 12,26 & $27,93 \%$ & $-27,27 \%$ & $0,00 \%$ & $0,00 \%$ \\
\hline producto/marca135 & $0,32 \%$ & $1,44 \%$ & 4,61 & 20,59 & $8,13 \%$ & $0,00 \%$ & $0,00 \%$ & $0,00 \%$ \\
\hline producto/marca136 & $0,09 \%$ & $5,70 \%$ & 0,60 & 22,12 & $35,66 \%$ & $-26,29 \%$ & $0,00 \%$ & $0,00 \%$ \\
\hline producto/marca137 & $0,53 \%$ & $3,26 \%$ & 7,61 & 64,17 & $31,87 \%$ & $0,00 \%$ & $0,00 \%$ & $0,00 \%$ \\
\hline producto/marca138 & $0,28 \%$ & $1,60 \%$ & 7,19 & 53,32 & $12,90 \%$ & $0,00 \%$ & $0,00 \%$ & $0,00 \%$ \\
\hline producto/marca139 & $-0,13 \%$ & $1,08 \%$ & $-1,67$ & 25,09 & $6,71 \%$ & $-6,29 \%$ & $0,00 \%$ & $0,00 \%$ \\
\hline producto/marca140 & $0,05 \%$ & $0,65 \%$ & 12,17 & 148,00 & $7,94 \%$ & $0,00 \%$ & $0,00 \%$ & $0,00 \%$ \\
\hline producto/marca141 & $1,11 \%$ & $5,95 \%$ & 1,60 & 7,75 & $26,65 \%$ & $-17,52 \%$ & $0,00 \%$ & $0,00 \%$ \\
\hline producto/marca 142 & $-0,28 \%$ & $5,90 \%$ & $-0,13$ & 17,36 & $37,37 \%$ & $-27,21 \%$ & $0,00 \%$ & $0,00 \%$ \\
\hline producto/marca143 & $0,22 \%$ & $3,20 \%$ & 3,27 & 33,84 & $21,78 \%$ & $-16,71 \%$ & $0,00 \%$ & $0,00 \%$ \\
\hline producto/marca144 & $0,30 \%$ & $1,51 \%$ & 5,03 & 24,74 & $10,25 \%$ & $0,00 \%$ & $0,00 \%$ & $0,00 \%$ \\
\hline producto/marca145 & $1,07 \%$ & $3,64 \%$ & 4,03 & 17,97 & $25,31 \%$ & $0,00 \%$ & $0,00 \%$ & $0,00 \%$ \\
\hline producto/marca146 & $0,97 \%$ & $2,86 \%$ & 3,22 & 10,62 & $15,54 \%$ & $0,00 \%$ & $0,00 \%$ & $0,00 \%$ \\
\hline producto/marca147 & $0,97 \%$ & $3,21 \%$ & 4,34 & 21,94 & $21,31 \%$ & $-1,39 \%$ & $0,00 \%$ & $0,00 \%$ \\
\hline producto/marca148 & $0,93 \%$ & $2,78 \%$ & 3,26 & 10,95 & $15,38 \%$ & $0,00 \%$ & $0,00 \%$ & $0,00 \%$ \\
\hline producto/marca149 & $0,91 \%$ & $4,03 \%$ & 2,00 & 25,29 & $29,21 \%$ & $-22,61 \%$ & $0,00 \%$ & $0,00 \%$ \\
\hline producto/marca 150 & $0,66 \%$ & $5,67 \%$ & 4,44 & 39,40 & $42,86 \%$ & $-28,16 \%$ & $0,00 \%$ & $0,00 \%$ \\
\hline producto/marca 151 & $0,63 \%$ & $2,36 \%$ & 4,41 & 22,03 & $17,47 \%$ & $0,00 \%$ & $0,00 \%$ & $0,00 \%$ \\
\hline producto/marca 152 & $0,55 \%$ & $2,27 \%$ & 4,64 & 25,76 & $17,47 \%$ & $-3,71 \%$ & $0,00 \%$ & $0,00 \%$ \\
\hline producto/marca 153 & $0,57 \%$ & $4,73 \%$ & 7,56 & 82,74 & $49,88 \%$ & $-17,95 \%$ & $0,00 \%$ & $0,00 \%$ \\
\hline producto/marca154 & $0,69 \%$ & $2,44 \%$ & 4,00 & 18,96 & $17,47 \%$ & $-3,71 \%$ & $0,00 \%$ & $0,00 \%$ \\
\hline producto/marca155 & $0,49 \%$ & $4,45 \%$ & 9,44 & 104,86 & $49,88 \%$ & $-9,81 \%$ & $0,00 \%$ & $0,00 \%$ \\
\hline producto/marca156 & $0,23 \%$ & $1,32 \%$ & 5,87 & 34,08 & $9,05 \%$ & $0,00 \%$ & $0,00 \%$ & $0,00 \%$ \\
\hline producto/marca157 & $0,92 \%$ & $4,81 \%$ & 7,03 & 74,75 & $49,88 \%$ & $-17,95 \%$ & $0,00 \%$ & $0,00 \%$ \\
\hline producto/marca158 & $0,32 \%$ & $1,66 \%$ & 2,79 & 13,77 & $8,95 \%$ & $-5,48 \%$ & $0,00 \%$ & $0,00 \%$ \\
\hline producto/marca159 & $0,50 \%$ & $1,89 \%$ & 3,18 & 11,68 & $10,02 \%$ & $-5,06 \%$ & $0,00 \%$ & $0,00 \%$ \\
\hline
\end{tabular}




\begin{tabular}{|c|c|c|c|c|c|c|c|c|}
\hline producto/marca160 & $0,51 \%$ & $2,16 \%$ & 3,01 & 11,54 & $11,96 \%$ & $-5,48 \%$ & $0,00 \%$ & $0,00 \%$ \\
\hline producto/marca161 & $0,09 \%$ & $0,80 \%$ & 8,52 & 71,53 & $7,06 \%$ & $0,00 \%$ & $0,00 \%$ & $0,00 \%$ \\
\hline producto/marca162 & $0,50 \%$ & $5,16 \%$ & 6,14 & 49,10 & $40,77 \%$ & $-15,05 \%$ & $0,00 \%$ & $0,00 \%$ \\
\hline producto/marca163 & $0,06 \%$ & $2,29 \%$ & $-3,96$ & 61,69 & $12,16 \%$ & $-21,57 \%$ & $0,00 \%$ & $0,00 \%$ \\
\hline producto/marca164 & $0,43 \%$ & $5,53 \%$ & 7,77 & 89,22 & $58,92 \%$ & $-24,54 \%$ & $0,00 \%$ & $0,00 \%$ \\
\hline producto/marca165 & $0,19 \%$ & $1,35 \%$ & 7,48 & 57,48 & $12,20 \%$ & $0,00 \%$ & $0,00 \%$ & $0,00 \%$ \\
\hline producto/marca166 & $0,19 \%$ & $1,66 \%$ & 8,50 & 71,41 & $14,71 \%$ & $-0,82 \%$ & $0,00 \%$ & $0,00 \%$ \\
\hline producto/marca167 & $0,23 \%$ & $1,85 \%$ & 9,40 & 95,92 & $20,22 \%$ & $0,00 \%$ & $0,00 \%$ & $0,00 \%$ \\
\hline producto/marca 168 & $0,52 \%$ & $1,93 \%$ & 3,86 & 14,67 & $11,58 \%$ & $-0,35 \%$ & $0,00 \%$ & $0,00 \%$ \\
\hline producto/marca169 & $0,67 \%$ & $2,28 \%$ & 3,63 & 13,10 & $13,72 \%$ & $0,00 \%$ & $0,00 \%$ & $0,00 \%$ \\
\hline producto/marca170 & $0,66 \%$ & $3,31 \%$ & 1,25 & 7,68 & $13,38 \%$ & $-11,65 \%$ & $0,00 \%$ & $0,00 \%$ \\
\hline producto/marca171 & $0,79 \%$ & $4,00 \%$ & 6,45 & 46,63 & $35,09 \%$ & $0,00 \%$ & $0,00 \%$ & $0,00 \%$ \\
\hline producto/marca172 & $0,56 \%$ & $1,98 \%$ & 3,70 & 14,26 & $12,06 \%$ & $-1,69 \%$ & $0,00 \%$ & $0,00 \%$ \\
\hline producto/marca173 & $0,01 \%$ & $3,37 \%$ & $-4,60$ & 39,97 & $12,00 \%$ & $-24,61 \%$ & $0,00 \%$ & $0,00 \%$ \\
\hline producto/marca174 & $0,05 \%$ & $0,60 \%$ & 12,17 & 148,00 & $7,31 \%$ & $0,00 \%$ & $0,00 \%$ & $0,00 \%$ \\
\hline producto/marca175 & $0,00 \%$ & $3,65 \%$ & $-5,12$ & 42,97 & $12,00 \%$ & $-27,25 \%$ & $0,00 \%$ & $0,00 \%$ \\
\hline producto/marca176 & $0,56 \%$ & $4,26 \%$ & 7,14 & 67,91 & $42,86 \%$ & $-10,76 \%$ & $0,00 \%$ & $0,00 \%$ \\
\hline producto/marca177 & $0,39 \%$ & $1,77 \%$ & 4,97 & 25,28 & $12,00 \%$ & $0,00 \%$ & $0,00 \%$ & $0,00 \%$ \\
\hline producto/marca178 & $0,74 \%$ & $4,18 \%$ & 7,66 & 67,49 & $41,85 \%$ & $0,00 \%$ & $0,00 \%$ & $0,00 \%$ \\
\hline producto/marca179 & $0,23 \%$ & $1,82 \%$ & 9,41 & 95,80 & $19,82 \%$ & $0,00 \%$ & $0,00 \%$ & $0,00 \%$ \\
\hline producto/marca 180 & $0,23 \%$ & $1,86 \%$ & 9,30 & 93,02 & $20,11 \%$ & $0,00 \%$ & $0,00 \%$ & $0,00 \%$ \\
\hline producto/marca181 & $0,74 \%$ & $4,18 \%$ & 7,66 & 67,49 & $41,85 \%$ & $0,00 \%$ & $0,00 \%$ & $0,00 \%$ \\
\hline producto/marca182 & $0,56 \%$ & $4,26 \%$ & 2,82 & 36,43 & $33,63 \%$ & $-25,17 \%$ & $0,00 \%$ & $0,00 \%$ \\
\hline producto/marca 183 & $0,44 \%$ & $2,97 \%$ & 9,68 & 103,88 & $33,33 \%$ & $0,00 \%$ & $0,00 \%$ & $0,00 \%$ \\
\hline producto/marca184 & $0,23 \%$ & $1,86 \%$ & 9,28 & 92,38 & $20,00 \%$ & $0,00 \%$ & $0,00 \%$ & $0,00 \%$ \\
\hline producto/marca185 & $0,39 \%$ & $3,63 \%$ & 11,18 & 130,03 & $42,86 \%$ & $0,00 \%$ & $0,00 \%$ & $0,00 \%$ \\
\hline producto/marca186 & $0,10 \%$ & $1,17 \%$ & 12,17 & 148,00 & $14,29 \%$ & $0,00 \%$ & $0,00 \%$ & $0,00 \%$ \\
\hline producto/marca187 & $0,90 \%$ & $5,23 \%$ & 7,29 & 55,89 & $42,86 \%$ & $0,00 \%$ & $0,00 \%$ & $0,00 \%$ \\
\hline producto/marca 188 & $-0,07 \%$ & $2,98 \%$ & $-6,35$ & 72,73 & $12,18 \%$ & $-29,98 \%$ & $0,00 \%$ & $0,00 \%$ \\
\hline producto/marca189 & $0,11 \%$ & $0,61 \%$ & 6,68 & 46,52 & $4,93 \%$ & $0,00 \%$ & $0,00 \%$ & $0,00 \%$ \\
\hline producto/marca190 & $0,48 \%$ & $3,40 \%$ & 2,14 & 33,79 & $26,26 \%$ & $-20,80 \%$ & $0,00 \%$ & $0,00 \%$ \\
\hline producto/marca191 & $0,17 \%$ & $1,11 \%$ & 7,02 & 50,26 & $8,74 \%$ & $0,00 \%$ & $0,00 \%$ & $0,00 \%$ \\
\hline producto/marca192 & $0,17 \%$ & $1,11 \%$ & 7,02 & 50,26 & $8,74 \%$ & $0,00 \%$ & $0,00 \%$ & $0,00 \%$ \\
\hline producto/marca193 & $0,15 \%$ & $1,09 \%$ & 7,34 & 53,97 & $8,74 \%$ & $0,00 \%$ & $0,00 \%$ & $0,00 \%$ \\
\hline producto/marca194 & $0,37 \%$ & $1,85 \%$ & 1,44 & 14,66 & $8,92 \%$ & $-10,13 \%$ & $0,00 \%$ & $0,00 \%$ \\
\hline producto/marca195 & $0,17 \%$ & $2,11 \%$ & 12,17 & 148,00 & $25,73 \%$ & $0,00 \%$ & $0,00 \%$ & $0,00 \%$ \\
\hline producto/marca196 & $0,17 \%$ & $2,11 \%$ & 12,17 & 148,00 & $25,73 \%$ & $0,00 \%$ & $0,00 \%$ & $0,00 \%$ \\
\hline producto/marca197 & $0,17 \%$ & $2,11 \%$ & 12,17 & 148,00 & $25,73 \%$ & $0,00 \%$ & $0,00 \%$ & $0,00 \%$ \\
\hline producto/marca198 & $0,18 \%$ & $1,59 \%$ & 8,98 & 82,14 & $16,08 \%$ & $0,00 \%$ & $0,00 \%$ & $0,00 \%$ \\
\hline producto/marca199 & $0,62 \%$ & $3,09 \%$ & 1,84 & 10,21 & $14,69 \%$ & $-12,81 \%$ & $0,00 \%$ & $0,00 \%$ \\
\hline producto/marca200 & $0,61 \%$ & $2,49 \%$ & 4,46 & 20,15 & $16,32 \%$ & $0,00 \%$ & $0,00 \%$ & $0,00 \%$ \\
\hline producto/marca201 & $0,17 \%$ & $1,18 \%$ & 7,01 & 48,33 & $8,98 \%$ & $-0,14 \%$ & $0,00 \%$ & $0,00 \%$ \\
\hline producto/marca202 & $0,82 \%$ & $3,48 \%$ & 0,81 & 10,97 & $15,17 \%$ & $-18,34 \%$ & $0,00 \%$ & $0,00 \%$ \\
\hline producto/marca203 & $0,31 \%$ & $2,58 \%$ & 2,03 & 24,28 & $17,68 \%$ & $-14,45 \%$ & $0,00 \%$ & $0,00 \%$ \\
\hline producto/marca204 & $0,70 \%$ & $3,04 \%$ & 2,83 & 13,01 & $19,72 \%$ & $-6,92 \%$ & $0,00 \%$ & $0,00 \%$ \\
\hline producto/marca205 & $0,08 \%$ & $1,17 \%$ & 11,38 & 137,01 & $13,92 \%$ & $-2,77 \%$ & $0,00 \%$ & $0,00 \%$ \\
\hline producto/marca206 & $0,26 \%$ & $2,13 \%$ & 5,53 & 40,64 & $15,75 \%$ & $-7,89 \%$ & $0,00 \%$ & $0,00 \%$ \\
\hline producto/marca 207 & $3,12 \%$ & $16,32 \%$ & 1,46 & 3,61 & $66,67 \%$ & $-40,00 \%$ & $0,00 \%$ & $0,00 \%$ \\
\hline producto/marca208 & $0,18 \%$ & $1,14 \%$ & 6,73 & 45,65 & $8,65 \%$ & $0,00 \%$ & $0,00 \%$ & $0,00 \%$ \\
\hline producto/marca209 & $1,04 \%$ & $8,32 \%$ & 3,13 & 19,82 & $48,32 \%$ & $-30,63 \%$ & $0,00 \%$ & $0,00 \%$ \\
\hline producto/marca 210 & $0,09 \%$ & $0,89 \%$ & 11,08 & 127,56 & $10,40 \%$ & $0,00 \%$ & $0,00 \%$ & $0,00 \%$ \\
\hline producto/marca211 & $0,00 \%$ & $0,00 \%$ & & & $0,00 \%$ & $0,00 \%$ & $0,00 \%$ & $0,00 \%$ \\
\hline producto/marca 212 & $0,04 \%$ & $0,50 \%$ & 12,17 & 148,00 & $6,03 \%$ & $0,00 \%$ & $0,00 \%$ & $0,00 \%$ \\
\hline producto/marca213 & $0,41 \%$ & $2,29 \%$ & 1,57 & 10,08 & $11,05 \%$ & $-9,68 \%$ & $0,00 \%$ & $0,00 \%$ \\
\hline producto/marca 214 & $0,48 \%$ & $1,97 \%$ & 4,59 & 22,71 & $14,39 \%$ & $0,00 \%$ & $0,00 \%$ & $0,00 \%$ \\
\hline producto/marca 215 & $0,45 \%$ & $1,80 \%$ & 4,20 & 17,23 & $10,78 \%$ & $0,00 \%$ & $0,00 \%$ & $0,00 \%$ \\
\hline producto/marca216 & $3,36 \%$ & $12,16 \%$ & 2,30 & 7,33 & $57,29 \%$ & $-27,79 \%$ & $0,00 \%$ & $0,00 \%$ \\
\hline producto/marca217 & $1,20 \%$ & $4,59 \%$ & 4,17 & 17,10 & $26,31 \%$ & $0,00 \%$ & $0,00 \%$ & $0,00 \%$ \\
\hline producto/marca 218 & $0,64 \%$ & $2,75 \%$ & 4,78 & 24,02 & $18,91 \%$ & $-1,27 \%$ & $0,00 \%$ & $0,00 \%$ \\
\hline producto/marca219 & $0,31 \%$ & $2,18 \%$ & 6,89 & 46,22 & $16,21 \%$ & $0,00 \%$ & $0,00 \%$ & $0,00 \%$ \\
\hline
\end{tabular}




\begin{tabular}{|c|c|c|c|c|c|c|c|c|}
\hline producto/marca220 & $0,00 \%$ & $0,00 \%$ & & & $0,00 \%$ & $0,00 \%$ & $0,00 \%$ & $0,00 \%$ \\
\hline producto/marca 221 & $0,00 \%$ & $0,00 \%$ & & & $0,00 \%$ & $0,00 \%$ & $0,00 \%$ & $0,00 \%$ \\
\hline producto/marca222 & $0,26 \%$ & $1,83 \%$ & 7,14 & 50,86 & $15,06 \%$ & $-0,43 \%$ & $0,00 \%$ & $0,00 \%$ \\
\hline producto/marca223 & $0,17 \%$ & $1,48 \%$ & 9,01 & 82,77 & $15,03 \%$ & $0,00 \%$ & $0,00 \%$ & $0,00 \%$ \\
\hline producto/marca224 & $0,16 \%$ & $1,20 \%$ & 8,35 & 71,50 & $11,52 \%$ & $0,00 \%$ & $0,00 \%$ & $0,00 \%$ \\
\hline producto/marca 225 & $0,16 \%$ & $1,25 \%$ & 8,41 & 72,46 & $11,99 \%$ & $0,00 \%$ & $0,00 \%$ & $0,00 \%$ \\
\hline producto/marca226 & $0,20 \%$ & $1,18 \%$ & 5,95 & 34,14 & $7,62 \%$ & $0,00 \%$ & $0,00 \%$ & $0,00 \%$ \\
\hline producto/marca227 & $0,87 \%$ & $2,76 \%$ & 3,56 & 13,36 & $15,76 \%$ & $0,00 \%$ & $0,00 \%$ & $0,00 \%$ \\
\hline producto/marca 228 & $0,50 \%$ & $1,85 \%$ & 3,67 & 12,44 & $10,08 \%$ & $0,00 \%$ & $0,00 \%$ & $0,00 \%$ \\
\hline producto/marca229 & $0,13 \%$ & $1,03 \%$ & 8,42 & 73,47 & $10,04 \%$ & $-0,10 \%$ & $0,00 \%$ & $0,00 \%$ \\
\hline producto/marca 230 & $0,21 \%$ & $1,28 \%$ & 5,97 & 34,47 & $8,51 \%$ & $0,00 \%$ & $0,00 \%$ & $0,00 \%$ \\
\hline producto/marca231 & $0,52 \%$ & $2,37 \%$ & 4,93 & 24,56 & $16,16 \%$ & $0,00 \%$ & $0,00 \%$ & $0,00 \%$ \\
\hline producto/marca 232 & $0,56 \%$ & $2,83 \%$ & 2,74 & 14,05 & $16,16 \%$ & $-10,54 \%$ & $0,00 \%$ & $0,00 \%$ \\
\hline producto/marca233 & $1,06 \%$ & $7,38 \%$ & 3,18 & 21,80 & $42,86 \%$ & $-29,98 \%$ & $0,00 \%$ & $0,00 \%$ \\
\hline producto/marca234 & $0,47 \%$ & $4,32 \%$ & 5,68 & 69,32 & $42,86 \%$ & $-22,91 \%$ & $0,00 \%$ & $0,00 \%$ \\
\hline producto/marca235 & $0,90 \%$ & $3,31 \%$ & 2,27 & 7,82 & $16,16 \%$ & $-10,54 \%$ & $0,00 \%$ & $0,00 \%$ \\
\hline producto/marca236 & $0,20 \%$ & $1,21 \%$ & 5,92 & 33,64 & $7,81 \%$ & $0,00 \%$ & $0,00 \%$ & $0,00 \%$ \\
\hline producto/marca237 & $0,39 \%$ & $3,57 \%$ & 11,67 & 139,52 & $42,95 \%$ & $0,00 \%$ & $0,00 \%$ & $0,00 \%$ \\
\hline producto/marca 238 & $0,94 \%$ & $6,74 \%$ & 4,79 & 29,77 & $42,86 \%$ & $-20,05 \%$ & $0,00 \%$ & $0,00 \%$ \\
\hline producto/marca239 & $1,46 \%$ & $7,46 \%$ & 5,74 & 33,85 & $51,79 \%$ & $-0,83 \%$ & $0,00 \%$ & $0,00 \%$ \\
\hline producto/marca240 & $0,47 \%$ & $7,89 \%$ & 3,91 & 44,50 & $66,69 \%$ & $-40,01 \%$ & $0,00 \%$ & $0,00 \%$ \\
\hline producto/marca241 & $0,07 \%$ & $0,57 \%$ & 8,55 & 72,29 & $5,17 \%$ & $0,00 \%$ & $0,00 \%$ & $0,00 \%$ \\
\hline producto/marca242 & $0,67 \%$ & $3,83 \%$ & 2,20 & 32,07 & $29,44 \%$ & $-22,74 \%$ & $0,00 \%$ & $0,00 \%$ \\
\hline producto/marca 243 & $0,31 \%$ & $4,65 \%$ & 7,17 & 73,87 & $46,67 \%$ & $-19,09 \%$ & $0,00 \%$ & $0,00 \%$ \\
\hline producto/marca244 & $0,34 \%$ & $1,73 \%$ & 5,94 & 38,14 & $14,31 \%$ & $0,00 \%$ & $0,00 \%$ & $0,00 \%$ \\
\hline producto/marca245 & $0,42 \%$ & $3,62 \%$ & 6,54 & 50,83 & $31,87 \%$ & $-8,33 \%$ & $0,00 \%$ & $0,00 \%$ \\
\hline producto/marca246 & $0,76 \%$ & $5,08 \%$ & 7,92 & 63,97 & $42,86 \%$ & $0,00 \%$ & $0,00 \%$ & $0,00 \%$ \\
\hline producto/marca247 & $0,06 \%$ & $0,72 \%$ & 12,17 & 148,00 & $8,78 \%$ & $0,00 \%$ & $0,00 \%$ & $0,00 \%$ \\
\hline producto/marca 248 & $0,58 \%$ & $7,89 \%$ & 4,15 & 55,60 & $73,33 \%$ & $-42,30 \%$ & $0,00 \%$ & $0,00 \%$ \\
\hline producto/marca249 & $0,24 \%$ & $1,46 \%$ & 6,22 & 38,08 & $10,50 \%$ & $0,00 \%$ & $0,00 \%$ & $0,00 \%$ \\
\hline producto/marca 250 & $0,21 \%$ & $1,47 \%$ & 4,23 & 23,02 & $9,01 \%$ & $-3,69 \%$ & $0,00 \%$ & $0,00 \%$ \\
\hline Harina de trigo & $0,00 \%$ & $0,00 \%$ & & & $0,00 \%$ & $0,00 \%$ & $0,00 \%$ & $0,00 \%$ \\
\hline Huevos & $0,04 \%$ & $0,43 \%$ & 12,17 & 148,00 & $5,28 \%$ & $0,00 \%$ & $0,00 \%$ & $0,00 \%$ \\
\hline $\begin{array}{l}\text { Leche fresca entera } \\
\text { sachet }\end{array}$ & $0,12 \%$ & $1,33 \%$ & 11,95 & 144,22 & $16,08 \%$ & $0,00 \%$ & $0,00 \%$ & $0,00 \%$ \\
\hline Combustibles y & & & & & & & & \\
\hline lubricantes & $0,23 \%$ & $1,83 \%$ & 9,38 & 95,49 & $19,91 \%$ & $0,00 \%$ & $0,00 \%$ & $0,00 \%$ \\
\hline compra & $0,53 \%$ & $2,26 \%$ & 4,90 & 24,82 & $15,50 \%$ & $0,00 \%$ & $0,00 \%$ & $0,00 \%$ \\
\hline venta & $0,18 \%$ & $1,16 \%$ & 6,76 & 45,82 & $8,77 \%$ & $0,00 \%$ & $0,00 \%$ & $0,00 \%$ \\
\hline dolarprom & $0,43 \%$ & $5,32 \%$ & 6,44 & 56,83 & $42,85 \%$ & $-22,63 \%$ & $0,00 \%$ & $0,00 \%$ \\
\hline brecha & $0,40 \%$ & $5,39 \%$ & 6,14 & 53,94 & $42,85 \%$ & $-22,98 \%$ & $0,00 \%$ & $0,00 \%$ \\
\hline varcpa & 0,00 & 0,03 & 3,84 & 26,71 & 0,21 & 0,06 & - & - \\
\hline varvta & 0,00 & 0,06 & 1,05 & 4,32 & 0,25 & 0,13 & - & - \\
\hline volatcompra & 0,01 & 0,02 & 3,74 & 20,21 & 0,16 & 0,07 & - & - \\
\hline volatventa & 0,00 & 0,01 & 6,65 & 45,24 & 0,07 & - & - & - \\
\hline cantoperac & 0,00 & 0,01 & 5,96 & 34,17 & 0,08 & - & - & - \\
\hline dummys 1 & 0,01 & 0,04 & 6,21 & 44,76 & 0,32 & 0,00 & - & - \\
\hline dummys 2 & 0,00 & 0,01 & 6,89 & 52,40 & 0,13 & - & - & - \\
\hline dummys 3 & - & - & & & - & - & - & - \\
\hline $\operatorname{mes} 12$ & 0,00 & 0,02 & 4,01 & 23,22 & 0,16 & 0,07 & - & - \\
\hline mes 1 & 0,00 & 0,02 & 2,78 & 11,09 & 0,09 & 0,07 & - & - \\
\hline mes 2 & 0,01 & 0,03 & 2,64 & 9,56 & 0,12 & 0,09 & - & - \\
\hline mes3 & 0,00 & 0,01 & 7,58 & 58,04 & 0,09 & - & - & - \\
\hline mes4 & 0,00 & 0,01 & 6,39 & 41,15 & 0,07 & - & - & - \\
\hline mes 5 & 0,01 & 0,05 & 2,26 & 9,47 & 0,21 & 0,17 & - & - \\
\hline mes6 & 0,01 & 0,04 & 2,44 & 21,63 & 0,25 & 0,20 & - & - \\
\hline mes 7 & 0,01 & 0,07 & 1,46 & 10,85 & 0,40 & 0,26 & - & - \\
\hline mes8 & 0,00 & 0,01 & 5,95 & 34,10 & 0,08 & - & - & - \\
\hline mes9 & 0,00 & 0,01 & 12,17 & 148,00 & 0,08 & - & - & - \\
\hline mes 10 & 0,00 & 0,01 & 12,17 & 148,00 & 0,14 & - & - & - \\
\hline
\end{tabular}




\begin{tabular}{lcccccccc} 
kurtc & 0,00 & 0,02 & 9,50 & 97,43 & 0,20 & - & - & - \\
kurtv & 0,00 & 0,02 & 9,41 & 96,12 & 0,20 & - & - & - \\
skewpc & 0,00 & 0,03 & 8,24 & 71,25 & 0,30 & - & - & - \\
skewpv & 0,00 & 0,04 & 7,09 & 63,86 & 0,43 & $-0,15$ & - & - \\
ano2016 & 0,00 & 0,01 & 12,17 & 148,00 & 0,10 & - & - & - \\
ano2017 & 0,00 & 0,01 & 8,54 & 72,07 & 0,11 & - & - & - \\
ano2018 & 0,00 & 0,02 & 6,02 & 35,26 & 0,13 & - & - & - \\
\hline
\end{tabular}

Tabla 5. Estadísticas descriptivas divididas según efectos between o within.

\begin{tabular}{|c|c|c|c|c|c|c|}
\hline Variable & & Media & $\begin{array}{l}\text { Desviación } \\
\text { estándar }\end{array}$ & Mínimo & Máximo & Observaciones \\
\hline \multirow[t]{3}{*}{ inflación } & overall & 0.003744 & 0.0367565 & -0.4306999 & 0.7565429 & $\mathrm{~N}=41420$ \\
\hline & between & & 0.0041175 & -0.0067097 & 0.0336373 & $\mathrm{n}=280$ \\
\hline & within & & 0.0365259 & -0.4374083 & 0.7498346 & $\mathrm{~T}-\mathrm{b} a r=147.929$ \\
\hline \multirow[t]{3}{*}{ Market power } & overall & 0.131924 & 0.158866 & 0.0154 & 0.49 & $\mathrm{~N}=41292$ \\
\hline & between & & 0.1591496 & 0.0154 & 0.49 & $\mathrm{n}=279$ \\
\hline & within & & $1.71 \mathrm{E}-16$ & 0.131924 & 0.131924 & $\mathrm{~T}=$ \\
\hline \multirow[t]{3}{*}{ IHH } & overall & 417.8876 & 820.5245 & 2.3716 & 2401 & $\mathrm{~N}=41292$ \\
\hline & between & & 821.989 & 2.3716 & 2401 & $\mathrm{n}=279$ \\
\hline & within & & $1.42 \mathrm{E}-14$ & 417.8876 & 417.8876 & $\mathrm{~T}=$ \\
\hline \multirow[t]{3}{*}{ Peso } & overall & 0.2987099 & 0.9627671 & 0.018 & 16 & $\mathrm{~N}=40552$ \\
\hline & between & & 0.9645169 & 0.018 & 16 & $\mathrm{n}=274$ \\
\hline & within & & $6.26 \mathrm{E}-16$ & 0.2987099 & 0.2987099 & $\mathrm{~T}=$ \\
\hline \multirow[t]{3}{*}{ Supermercado } & overall & 0.0175781 & 0.1314129 & 0 & 1 & $N=75776$ \\
\hline & between & & 0.1763898 & 0 & 1 & $\mathrm{n}=281$ \\
\hline & within & & 0 & 0.0175781 & 0.0175781 & $\mathrm{~T}-\mathrm{bar}=269.665$ \\
\hline \multirow[t]{3}{*}{ Harina } & overall & 0.0050697 & 0.0258242 & -0.0479726 & 0.1594588 & $\mathrm{~N}=41440$ \\
\hline & between & & 0 & 0.0050697 & 0.0050697 & $\mathrm{n}=280$ \\
\hline & within & & 0.0258242 & -0.0479726 & 0.1594588 & $\mathrm{~T}=$ \\
\hline \multirow[t]{3}{*}{ Huevos } & overall & 0.0070006 & 0.0335527 & -0.1062535 & 0.1534501 & $\mathrm{~N}=41440$ \\
\hline & between & & 0 & 0.0070006 & 0.0070006 & $\mathrm{n}=280$ \\
\hline & within & & 0.0335527 & -0.1062535 & 0.1534501 & $\mathrm{~T}=148$ \\
\hline \multirow[t]{3}{*}{ Leche } & overall & 0.0067171 & 0.0324099 & -0.0959335 & 0.1393999 & $\mathrm{~N}=41440$ \\
\hline & between & & 0 & 0.0067171 & 0.0067171 & $\mathrm{n}=280$ \\
\hline & within & & 0.0324099 & -0.0959335 & 0.1393999 & $\mathrm{~T}=148$ \\
\hline \multirow[t]{3}{*}{ Combustible } & overall & 0.0082 & 0.0378013 & -0.132892 & 0.200489 & $\mathrm{~N}=41440$ \\
\hline & between & & 0 & 0.0082 & 0.0082 & $\mathrm{n}=280$ \\
\hline & within & & 0.0378013 & -0.132892 & 0.200489 & $\mathrm{~T}=148$ \\
\hline \multirow[t]{3}{*}{ Precio compra } & overall & 19.26318 & 6.937944 & 9.874444 & 37.67143 & $\mathrm{~N}=41440$ \\
\hline & between & & 0 & 19.26318 & 19.26318 & $\mathrm{n}=280$ \\
\hline & within & & 6.937944 & 9.874444 & 37.67143 & $\mathrm{~T}=148$ \\
\hline \multirow[t]{3}{*}{ Precio venta } & overall & 20.18924 & 7.431076 & 9.98 & 39.67143 & $\mathrm{~N}=41440$ \\
\hline & between & & 0 & 20.18924 & 20.18924 & $\mathrm{n}=280$ \\
\hline & within & & 7.431076 & 9.98 & 39.67143 & $\mathrm{~T}=$ \\
\hline \multirow[t]{3}{*}{ Brecha compra } & overall & 0.9256155 & 0.5068599 & 0.1055556 & 2.442857 & $\mathrm{~N}=41440$ \\
\hline & between & & 0 & 0.9256155 & 0.9256155 & $\mathrm{n}=280$ \\
\hline & within & & 0.5068599 & 0.1055556 & 2.442857 & $\mathrm{~T}=$ \\
\hline \multirow[t]{3}{*}{ Porcentaje variación } & overall & 0.0434923 & 0.0114115 & 0 & 0.0643432 & $\mathrm{~N}=41440$ \\
\hline & between & & 0 & 0.0434923 & 0.0434923 & $\mathrm{n}=280$ \\
\hline & within & & 0.0114115 & $6.94 \mathrm{E}-18$ & 0.0643432 & $\mathrm{~T}=148$ \\
\hline \multirow[t]{3}{*}{ Operaciones } & overall & 10.86486 & 4.796803 & 4 & 34 & $\mathrm{~N}=41440$ \\
\hline & between & & 0 & 10.86486 & 10.86486 & $\mathrm{n}=280$ \\
\hline & within & & 4.796803 & 4 & 34 & $\mathrm{~T}=$ \\
\hline
\end{tabular}

